NBSIR 88-3755

\title{
Naval Fire Fighting Trainers - Thermal Radiation Effects Associated with the 19F4 FFT
}

David W. Stroup

U.S. DEPARTMENT OF COMMERCE

National Bureau of Standards

National Engineering Laboratory

Center for Fire Research

Gaithersburg, MD 20899

May 1988

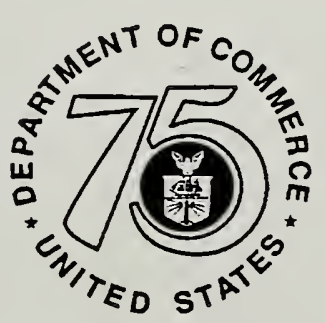

Sponsored by:

75 Yoere Stimulading Amertecis Progreses United States Navy Naval Training Systems Center Orlando, FL 

NBSIR 88-3755

NAVAL FIRE FIGHTING TRAINERS -

THERMAL RADIATION EFFECTS

ASSOCIATED WITH THE 19F4 FFT

David W. Stroup

U.S. DEPARTMENT OF COMMERCE

National Bureau of Standards

National Engineering Laboratory

Center for Fire Research

Gaithersburg, MD 20899

May 1988

Sponsored by:

United States Navy

Naval Training Systems Center

Orlando, FL

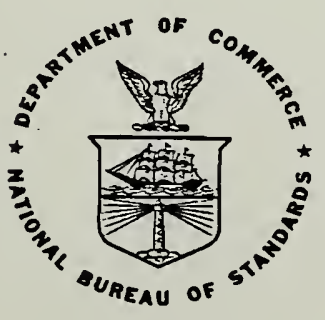

U.S. DEPARTMENT OF COMMERCE, C. William Verity, Secretary NATIONAL BUREAU OF STANDARDS, Ernest Ambler, Director 

LIST OF TABLES . . . . . . . . . . . . . . . . . . . . . iv

LIST OF FIGURES . . . . . . . . . . . . . . . . . . . . . . . . iv

NOMENCLATURE . . . . . . . . . . . . . . . . . . . . v

ABSTRACT . . . . . . . . . . . . . . . . . . . . . . . 1

1. INTRODUCTION . . . . . . . . . . . . . . . . . . . . . . . 2

2. SOLUTION METHODOLOGY ...................... . 4

2.1 Radiation Flux . . . . . . . . . . . . . . . . . . . . . . . 4

2.2 Configuration Factor . . . . . . . . . . . . . . . . . 10

2.2.1 Flame Height . . . . . . . . . . . . . . . . . . . 11

2.2.2 Wind Effects.................. . 14

2.2.3 Calculating View Factors . . . . . . . . . . . . . . . 15

2.3 Computer Program for Calculating Radiation Heat Flux . . . . . . 18

3. ANALYSIS OF $19 F 4$ TRAINER RADIATION EFFECTS ............. 19

4. SUMMARY . . . . . . . . . . . . . . . . . . . . . 23

5. REFERENCES . . . . . . . . . . . . . . . . . . . 24

APPENDIX A - Flame Temperature Calculations . . . . . . . . . . . . 39

APPENDIX B - Source Code for Radiation Heat Flux and Configuration Factor Computer Program . . . . . . . . . . 45 
Table 1. Properties of Propane . . . . . . . . . . . . . . . . . . 27

Table 2. Properties of Ambient Air . . . . . . . . . . . . . . . . . . 27

\section{LIST OF FIGURES}

Figure 1. Plan view of $19 F 4$ trainer facility . . . . . . . . . . . . . 28

Figure 2. Elevation view of $19 F 4$ trainer facility . . . . . . . . . . . 29

Figure 3. Maximum flow rate versus burner diameter for buoyancy driven, 16 foot high, turbulent propane flames (diameters between

0 and $100 \mathrm{ft}$ ) . . . . . . . . . . . . . . . . . 30

Figure 4. Maximum flow rate versus burner diameter for buoyancy driven, 16 foot high, turbulent propane flames (diameters between

0 and $5 \mathrm{ft}$ ).................... . . . . 31

Figure 5. Geometry used for calculation of view factors . . . . . . . 32

Figure 6. Geometric configuration for calculating view factors for right circular and inclined cylindrical sources . . . . . . . . . . 33

Figure 7. Flame length versus wind speed . . . . . . . . . . . . . . . . 34

Figure 8. Flame angle of tilt versus wind speed . . . . . . . . . . . . 35

Figure 9. Flame height above horizontal versus wind speed . . . . . . 36

Figure 10. Radiation flux versus distance from burner centerline for wind speeds of $0,5,10,25$, and $50 \mathrm{mph}$. . . . . . . . . . 37

Figure 11. Radiation flux versus distance from burner centerline for wind speeds of $0,5,10,25$, and $50 \mathrm{mph}$. . . . . . . . . . . . 38 


\section{NOMENCLATURE}

A

d

dA

$\dot{\mathrm{E}}_{\mathbf{r}}$

F

g

h

L

in"

r

$r_{f}$

S

$\mathrm{T}$

$\mathrm{u}$

$\dot{\mathrm{V}}$

$\beta$

$\Delta \mathrm{H}_{\mathrm{c}}$

$\epsilon$

$\nu_{a}$

$\rho$

$\sigma$

$\tau$

$x$

area

diameter of the fire at its base

area taken as a differential element

the radiative power output of the fire

a geometric "view factor" dependent on the relative flame and target geometry

acceleration of gravity

flame height or length/flame radius, dimensionless

flame height

mass burning rate per unit area of the fire source

distance from target element to flame element along a line

equivalent radius of fire area

distance to target from flame axis/flame radius, dimensionless

temperature

velocity

volume flow rate of fuel

angle between the normal to differential element $\mathrm{dA}$ and the line from the target to the radiation source

the heat of combustion of the fuel

emissivity of the flame

kinematic viscosity of ambient air

density

Stefan-Boltzmann constant ( $1.71 \times 10^{-9} \mathrm{Btu} / \mathrm{hr} \mathrm{ft}^{2} \mathrm{R}^{4}$ )

the transmissivity of the atmosphere to thermal radiation

the fraction of the fire's energy which is radiated 
Subscripts

$\begin{array}{ll}\text { a } & \text { ambient } \\ \text { v } & \text { fire or flame } \\ \text { w } & \text { fuel vapor } \\ 1 & \text { wind } \\ 2 & \text { radiation target } \\ & \text { radiation source }\end{array}$

Superscripts

* dimensionless quantity 


\section{NAVAL FIRE FIGHTING TRAINERS - THERMAL RADIATION EFFECTS ASSOCIATED WITH THE 19F4 FFT}

David W. Stroup

\section{ABSTRACT}

This report presents an analysis of the thermal radiation produced by flames from the U.S. Navy 19F4 Fire Fighter Training facility. The 19F4 facility is used to simulate airplane crash fires on aircraft carrier flight decks and aircraft carrying ships. A simple methodology for calculating radiative heat transfer to targets is developed from a review of available literature. Of particular importance is the influence of wind on flame size and shape, the calculation procedure accounts for this effect. The radiation heat fluxes at various distances from the trainer are presented in the form of graphs. The fluxes received by a crane and the $19 \mathrm{~F} 4$ instructor's tower adjacent to the facility are calculated and shown to be substantial under certain conditions. Recommendations for placement of the crane and the instructor's tower are provided.

Key words: aircraft carriers; aircraft carrying ships; aircraft fires; crash fires; fire fighting training; flame height; flame radiation; radiation heat flux; radiative heat transfer; thermal radiation; training devices; wind effects 


\section{INTRODUCTION}

The U.S. Navy Training Systems Center is engaged in the design and construction of several fire fighter training facilities in various areas of the country. These facilities include many different buildings and other structures designed to simulate various problems which may be encountered by Navy fire fighters.' This report describes results of an analysis of one training structure. The structure is designated 19F4. The 19F4 structure is designed to simulate crashed aircraft fires on the flight decks of both an aircraft carrier and a helicopter equipped surface ship. It consists of an open training deck measuring $112 \mathrm{ft}$ by $66 \mathrm{ft}$. A metal grate, $52 \mathrm{ft}$ by $36 \mathrm{ft}$, is located in the center of the training deck. The grating forms the floor of the training deck in this area and is used to cover the "fireplace". The "fireplace" is the source of the training fires. The remaining bounding areas of the training deck are constructed of concrete. In addition to real and mock-up fire fighting equipment located on the training deck, a crane with a thermal radiation shield is provided immediately adjacent to the "fireplace". A two story instructor's station is located approximately $50 \mathrm{ft}$ from a corner of the "fireplace" $[1]^{1}$. The burners located $4 \mathrm{ft}$ below the deck must produce flames $16 \mathrm{ft}$ in height (12 ft above the metal deck). A plan view of the 19F4 training facility is shown in figure 1 . Figure 2 presents an elevation view of the trainer including the crane. this report. 
This report analyzes the potential thermal radiation exposures associated with operation of the $19 F 4$ facility. A simple methodology for calculating the radiant heat transfer from large open fires to target objects is developed from a review of the available research into flame radiation. This calculation procedure is used to estimate the radiation heat flux at various distances from the trainer. The thermal radiation reaching the instructor's tower and the crane (and its radiation shield) and the resulting temperature increases are of particular concern. The radiation fluxes to these objects are specifically identified and compared to available measures of radiation hazard. Finally, recommendations for minimizing the effect of thermal radiation on these structures are presented.

The amount of radiant energy received by an object exposed to an open flame is influenced by a number of factors. These factors include: the flame size and shape, the flame emissive power, the transmissivity of the atmosphere, and the flame to target geometry. To the extent possible, values for these factors are calculated from the conditions associated with the $19 \mathrm{~F} 4$. At the time of this analysis, the design of the $19 F 4$ "fireplace" burner(s) has not been completed. In order to carry out this analysis, an important assumption must be made concerning the flames produced by this "fireplace". The burner or burners must produce buoyancy driven, turbulent flames. These are the type of flames that would be produced by a burning hydrocarbon pool. The properties of the flames are of fundamental importance in the determination of flame heights. 


\section{SOLUTION METHODOLOGY}

The general procedure for computing the radiant flux to a target surface outside a fire involves a series of calculations. The steps are as follows:

(1) calculate the flame shape, usually defined by centerline length and angle of inclination,

(2) calculate the flame emissivity,

(3) calculate the transmissivity of the atmosphere,

(4) calculate the geometric view factor of the target surface relative to the assumed flame shape, and finally,

(5) calculate the radiant flux incident on the target surface.

\subsection{Radiation Flux}

The radiation flux, $\dot{q} "$, incident on any target of interest located at some distance from a flame can be expressed by the general formula

$$
\dot{q}^{\prime \prime}=r \quad F \in \sigma T_{f}^{4}
$$

The emissivity, $\epsilon$, accounts for the fact that the flame is a gray emitter, i.e. not an ideal black body radiator. The flame emissivity is a combination of the emissivities of several combustion products (soot, water vapor, and carbon dioxide). Calculation of this combined emissivity is extremely difficult. In addition, the emissivity depends on the path length through the fire. 
For the purposes of this analysis, the flame emissivity, $\epsilon$, will be assumed to be 1. An optically thick flame that radiates as a black body would have an emissivity of one. Since the emissivity will vary depending on the trainer test conditions, an emissivity value of unity represents a worst case and thus is the most appropriate choice for a safety analysis.

The transmissivity of the atmosphere, $\tau$, reflects the fact that radiant energy from a flame is only partially transmitted by the atmosphere due to the presence of water vapor. The magnitude of the transmissivity depends on the spectral distribution of the flame radiation, on the length of the path to the target, and on the composition of the atmosphere, including especially the absolute humidity. While some data on transmissivity is available in the literature, a value of 1 (representing a clean, dry atmosphere) will be assumed for this analysis. Once again, this will simplify the calculations and provide results representative of the worst case situation.

The radiation "view factor", F, between a fire and a target element outside of the fire depends on the flame's shape, the relative distance between the fire and the receiving element, and the relative orientation of the element. In order to facilitate computation of the radiative flux at a target, a regular shape must be assumed for the flame, such as a parallelpiped or cylinder. The dimensions and angle of inclination of the shape are chosen to approximate the base area, the flame length, and the wind induced flame angle of tilt. 
The radiation temperature, $T_{f}$, of the flame is a difficult quantity to measure. However, the radiative power output from fires using propane or similar fuels has been studied and measured by several researchers $[2,3,4]$. The radiative power output per unit flame surface area is related to the radiation flame temperature according to the expression

$$
\dot{\mathrm{E}}_{\mathrm{r}}^{\prime \prime}=\epsilon \sigma \mathrm{T}_{f}^{4}
$$

Research by Markstein [2] on propane turbulent diffusion flames has shown a linear relationship between the radiative power output of the fire and the total fire heat release rate. Values for this ratio determined by Markstein experimentally range from 0.238 to 0.264 . Markstein's results [2] were obtained using small scale tests (fuel flow rates between 1.16 and 19.3 in. ${ }^{3} / \mathrm{s}$ and burner diameters from 3.7 in. to 7.9 in.). Hägglund and Persson [3] obtained similar results using square JP-4 pools ranging in size from 3.3 ft to $32.8 \mathrm{ft}$. Their results indicate that the percentage of fire energy released as radiation decreases with increasing fire size. Specifically, for the $3.3 \mathrm{ft}$ square fire, 39 percent of the total energy generated by the fire was released by radiation. This ratio decreased to 10 percent for the $32.8 \mathrm{ft}$ square fire [3].

For an arbitrary flame shape, this relationship may be expressed as

$$
\dot{\mathrm{E}}_{\mathrm{r}}^{\prime \prime}=\chi \Delta \mathrm{H}_{\mathrm{c}} \dot{\mathrm{m}} " \mathrm{~A}_{\mathrm{fire}} / \mathrm{A}_{\mathrm{flame}} \operatorname{surface}
$$


In equation (3), the quantity $A_{f i r e}$ refers to the area involved in the fire, and the quantity $A_{f l a m e}$ surface is the surface area of the flames. Implicit in this equation is the assumption that the radiative intensity is constant over the surface of the flame. If the fire is assumed to be shaped like a cylinder, $A_{f i r e}$ would be the area of the base of the cylinder while $A_{f l a m e}$ surface would be the surface area of the cylinder plus the area of its top and bottom. Since the exact $19 F 4$ burner geometry is not known, radiation to and/or from the top and bottom areas of the flame will be ignored. This will provide a worst case scenario. The effect of assuming different radiation fractions, $\chi$, will be analyzed later in this report.

Combining equations (2) and (3) yields:

$$
\dot{\mathrm{E}} "=\epsilon \sigma \mathrm{T}_{f}^{4}=\chi \Delta \mathrm{H}_{\mathrm{c}} \dot{\mathrm{m}}^{\prime \prime} \mathrm{A}_{\mathrm{fire}} / \mathrm{A}_{\mathrm{flame}} \text { surface }
$$

This equation expresses the radiative power output from the fire in terms of either the radiation flame temperature or the total fire energy generation rate.

Substituting equation (2) into equation (1) yields:

$$
\dot{q}^{\prime \prime}=\tau F \dot{E}_{r}^{\prime \prime}
$$

With the assumption of unity for atmospheric transmissivity and using equation (3), this equation reduces to 


$$
\dot{\mathrm{q}}^{\prime \prime}=\mathrm{F} \chi \Delta \mathrm{H}_{\mathrm{c}} \dot{\mathrm{m}}^{\prime \prime} \mathrm{A}_{\mathrm{fire}} / \mathrm{A}_{\mathrm{fl} \text { ame }} \text { surface }
$$

or

$$
\dot{\mathrm{q}}^{\prime \prime}=\mathrm{F} \times \Delta \mathrm{H}_{\mathrm{c}} \quad \dot{\mathrm{V}} \rho_{\mathrm{v}} /(\pi \mathrm{d} \mathrm{L})
$$

where $\dot{V}$ - volume flow rate of fuel,

$\rho_{\mathrm{v}}$ - density of fuel vapors,

d - diameter of the fire area, and

L - height of the flames.

Equation (7) is appropriate when the flame shape is assumed to be a cylinder and the volume flow rate of fuel is known. Equation (6) and its alternative formulation, equation (7), form the basis for the rest of the analysis presented in this paper.

Using the middle and right-hand parts of equation (4), it is possible to obtain the following expression for flame temperature:

$$
\mathrm{T}_{\mathrm{f}}=\left[\frac{\chi \Delta \mathrm{H}_{\mathrm{c}} \dot{\mathrm{m}}^{\prime \prime} \mathrm{A}_{\text {fire }}}{\epsilon \sigma \mathrm{A}_{\mathrm{flame}} \text { surface }}\right]^{1 / 4}
$$

Equation (8) can be used to evaluate the validity of the assumed flame shape and equation (6). For a parallelpiped flame shape, equation (8) becomes 


$$
\mathrm{T}_{\mathrm{f}}=\left[\frac{\chi \Delta \mathrm{H}_{\mathrm{c}} \dot{\mathrm{V}} \rho_{\mathrm{v}}}{\epsilon \sigma 2(\mathrm{x}+\mathrm{y}) \mathrm{L}}\right]^{1 / 4}
$$

where L - height of the parallelpiped,

$x$ - length of one side of the parallelpiped (parallel to the ground), and

$y$ - length of adjacent side of the parallelpiped.

Equation (8) for a cylindrical flame shape would be

$$
\mathrm{T}_{f}=\left[\frac{\chi \Delta \mathrm{H}_{\mathrm{c}} \dot{\mathrm{V}} \rho_{\mathrm{v}}}{\epsilon \sigma \pi \mathrm{d} \mathrm{L}}\right]^{1 / 4}
$$

where d - diameter of the cylinder base and

L - height of the cylinder.

(The top and bottom of the parallelpiped and the cylinder have been ignored in calculating the $A_{f 1 a m e}$ surface quantities used in equations (9) and (10).)

Using the data for propane from Table 1, a fuel flow rate of $27.5 \mathrm{ft}^{3} / \mathrm{s}$ (1650 $\left.\mathrm{ft}^{3} / \mathrm{min}\right)$, a flame height of $12 \mathrm{ft}$, and rectangular base dimensions of 52 ft by $36 \mathrm{ft}$, equation (9) yields a flame temperature of $2061 \mathrm{R}$. For a fire assumed to be shaped like a cylinder with a base diameter of $50 \mathrm{ft}$, the flame temperature calculated using equation (10) is $2121 \mathrm{R}$. Researchers studying radiation from flames generated by burning propane and/or polymethylmethacrylate (PMMA) have quoted radiation flame temperatures in the range 1800 
$R$ to $2500 R[2,5,6,7]$. Specifically, Orloff [6] has determined an average flame temperature of $2270 \mathrm{R}$ for PMMA burning at the rate of $0.0031 \mathrm{~b}_{\mathrm{m}} / \mathrm{ft} \mathrm{t}^{2} \mathrm{~s}$. Using equation (8), a conical flame shape, and Orloff's data [6], the flame temperature is estimated to be $2259 \mathrm{R}$. The details of how this flame temperature was calculated from Orloff's data [6] are shown in Appendix A.

The flame temperature values calculated here using various flame shapes agree quite well with the quoted values. This indicates that equation (6) and its alternative formulations are valid for use in this analysis.

\subsection{Configuration Factor}

The configuration or view factor represents the fraction of energy emitted from a surface that is incident on some receiving body. View factors depend on the size and shape of the source and the distance between the source and the target. A flame is a hot, luminous mass of burning gas which does not have a defined surface. The flame shape and size vary considerably during burning because of turbulence. Fortunately, fluctuations in the instantaneous flame geometry usually average out to a relatively constant value for a given fire over some period of time. In order to calculate view factors for flames, it is necessary to assume that the flame has some average shape and size.

The flame shape can be approximated as either a plane rectangular radiator or as a cylindrical radiator. Due to differences in configuration factors, a plane radiator yields a higher heat flux value than a cylindrical one. Reference [5] suggests that, in general, the cylindrical radiator 
assumption agrees more closely with experimental data than does a plane radiator. Using the cylindrical geometry, the target location relative to the source is not as important. The effect of using different flame shapes for calculating view factors will be analyzed later in this report.

When the exposure fire is not circular, the diameter of an equivalent circular area or the longest dimension of the rectangle may be used to calculate the view factor. Using the larger of these two dimensions will produce conservative results, i.e., higher heat flux values at a given distance.

\subsubsection{Flame Height}

For a fire having a specified diameter, d, it is necessary to know the flame height and the angle of inclination of the flame before a view factor can be computed. Numerous investigators $[8,9,10,11,12,13]$ have studied the relationship between fire diameter, energy release rate, and flame height. The flame height is generally defined as the height at which the flame is observed at or above that height $50 \%$ of the time. Several methods have been used to determine flame heights during fire tests. Visual observation tends to yield slight overestimates of flame heights. Video tape analysis or averaging a number of one-second-exposure photographs appear to yield acceptable results [14]. 
For buoyancy driven turbulent flames, there is general agreement among researchers that flame height is proportional to the rate of heat release to the two-fifths power divided by the diameter of the fire source. However, the recommended constant of proportionality for this relationship varies between 0.18 and 0.23 . The reader is referred to reference [14] for an excellent summary of available flame height correlations. In addition, reference [14] provides several general recommendations concerning calculation of flame heights.

Heskestad [9] has correlated data from a wide variety of sources, including pool fires using the equation

$$
L=0.23 \dot{q}_{c}^{2 / 5}-1.02 d
$$

The rate of energy generation by the fire, $\dot{q}_{c}$, may be related to its mass loss rate per unit fire area, $\dot{\mathrm{m}}$, according to

$$
\dot{q}_{c}=\dot{m}^{\prime \prime} \Delta \mathrm{H}_{c} A_{f}
$$

Using equation (12), equation (11) becomes

$$
\mathrm{L}=0.23\left(\dot{\mathrm{m}} " \Delta \mathrm{H}_{\mathrm{c}} \mathrm{A}_{\mathrm{f}}\right)^{2 / 5}-1.02 \mathrm{~d}
$$

The correlation has been shown to be very satisfactory, although it has not been tested outside the range $7<\dot{\mathrm{q}}_{\mathrm{c}}^{2 / 5} / \mathrm{d}<700 \mathrm{~kW}^{2 / 5} / \mathrm{m}$. Zukoski et al. [15] comment that for values of $\mathrm{L} / \mathrm{d}<1$, the flame breaks up into a number of small 
flamlets which are apparently independent. Such behavior has been observed in very large mass fires [16].

Figures 3 and 4 relate burner diameter to mass flow rate of fuel for 16 foot flame heights using equation (13). The $19 F 4$ will operate using flames 16 ft high (12 ft above the deck). Equation (13) indicates that 16 foot high flames would be obtained at a fuel flow rate of $1650 \mathrm{ft}^{3} / \mathrm{min}^{\prime}$ (19F4 specification) in a burn area $46 \mathrm{ft}$ in diameter. The Navy test facility is specified to have a rectangular burn area $36 \mathrm{ft}$ by $52 \mathrm{ft}$. So, this fuel flow rate is adequate for the test area based on analysis using the Heskestad equation.

A burning pool of hydrocarbon fuel would produce buoyancy driven flames. The upward velocity of these flames is driven by the density difference between the hot gases making up the flames and the ambient air. The fuel has no initial upward velocity. The flame height calculations discussed here assume that the flames are turbulent and buoyancy driven. The 19F4 training fires will be generated using a combination of several burners. If these burners are to simulate a pool fire, they must produce buoyancy driven flames. A burner design which will provide for immediate dissipation of the fuel velocity as it exits the burner should be developed. If it is assumed that each burner will produce a 16 foot high flame (12 ft above the grate), figures 3 and 4 together with equation (13) may be used to estimate the number of burners and their diameters required to produce turbulent, buoyancy driven flames. Equation (13) may be used to estimate similar results for flames of 
any assumed height. If the fuel has substantial velocity as it exits the burner, these flame height calculations will not be valid.

\subsubsection{Wind Effects}

The previous discussion relates to calculation of flame heights with no wind. The wind will influence the size and shape of flames. The flames will bend away from the wind and either elongate or shorten depending on the wind speed. Based on data obtained from experiments using wood cribs, Thomas [8] developed a correlation for determining flame lengths in the presence of wind. The correlation is

$$
\frac{\mathrm{L}}{\mathrm{d}}=55\left[\frac{\dot{\mathrm{m}}^{\prime \prime}}{\rho_{\mathrm{a}} \sqrt{\mathrm{gd}}}\right]^{0.67}\left[\mathrm{u}^{*}\right]^{-0.21}
$$

where $u^{*}$ is the nondimensional wind velocity given by

$$
u^{*}=\frac{u_{w}}{\left[\frac{g \dot{\mathrm{m}}^{\prime \prime} \mathrm{d}}{\rho_{\mathrm{v}}}\right]^{1 / 3}}
$$


The wind induced angle of tilt of the flame from the vertical can be predicted from the correlation of Welker and Sliepcevich [17]. This correlation was derived by making a fundamental momentum balance on the flame which is assumed to behave as a tethered balloon. The correlation was compared to experimental data obtained using fires ranging from 4 inches to more than $100 \mathrm{ft}$ in diameter. The correlation equation fits the data very we11. The flame angle, $\theta$, as measured from the vertical, is given by

$$
\frac{\tan \theta}{\cos \theta}=3.3\left[\frac{\mathrm{d} \mathrm{u}_{\mathrm{w}}}{\nu_{\mathrm{a}}}\right]^{0.07}\left[\frac{\mathrm{u}_{\mathrm{w}}^{2}}{\mathrm{gd}}\right]^{0.8}\left[\frac{\rho_{\mathrm{v}}}{\rho_{\mathrm{a}}}\right]^{-0.6}
$$

Equations (14), (15) and (16) may be used to characterize the size and shape of the flame in the presence of wind in order to calculate view factors.

\subsubsection{Calculating View Factors}

In general, the geometric view factor, $F$, in equation (1) can be obtained from

$$
\mathrm{F}_{\mathrm{dA}_{1}-\mathrm{A}_{2}}=\int_{\mathrm{A}_{2}}\left(\cos \beta_{1} \cos \beta_{2}\right) /\left(\pi \mathrm{r}^{2}\right) \mathrm{dA}_{2}
$$

where $\mathrm{dA}_{1}=$ target area, taken as a differential element

$$
A_{2}=\text { effective emitting area of flame }
$$


$r=$ distance from target element to flame element along a line from $d A_{1}$ to $d_{2}$

$\beta_{1}=$ angle between the normal to $\mathrm{dA}_{1}$ and the line from $\mathrm{dA}_{1}$ to $\mathrm{dA}_{2}$ $\beta_{2}=$ angle between the normal to $\mathrm{dA}_{2}$ and the line from $\mathrm{dA}_{1}$ to $\mathrm{dA}_{2}$. The geometry used for calculation of view factors is shown in figure 5 . Equation (17) must be integrated over the effective emitting area of the flame, $A_{2}$, that can be seen by a differential element of the target, $\mathrm{dA}_{1}$, to obtain the view factor. Textbooks and handbooks give algebraic solutions to equation (17) for particular geometries. In some books, the solutions are presented in the form of graphs.

In the solid flame model of radiation used in this analysis, the turbulent flame is approximated by a cylinder. Under conditions of no wind, the cylinder is vertical. In the presence of wind, the cylinder is assumed to be tilted. The two configurations are shown in figure 6 . The algebraic solutions for horizontal and vertical view factors for a vertical cylinder are given by Raj and Kalelkar [18] and Sparrow [19] as:

$$
\begin{aligned}
& F_{H}=\frac{1}{\pi}\left[\frac{(B-1 / S)}{B^{2}-1} \tan ^{-1}\left[\frac{(B+1)(S-1)}{(B-1)(S+1)}\right]^{1 / 2}\right. \\
& \left.\quad-\frac{(A-1 / S)}{A^{2}-1} \tan ^{-1}\left[\frac{(A+1)(S-1)}{(A-1)(S+1)}\right]^{1 / 2}\right] \\
& F_{V}=\frac{1}{\pi}\left[\frac{1}{S} \tan ^{-1} \frac{h}{S^{2}-1}-\frac{h}{S}\left[\tan ^{-1}\left[\frac{S-1}{S+1}\right]^{1 / 2}\right.\right.
\end{aligned}
$$




$$
\left.\left.-\frac{A}{A^{2}-1} \tan ^{-1}\left[\frac{(A+1)(S-1)}{(A-1)(S+1)}\right]^{1 / 2}\right]\right]
$$

where $h=L / r_{f}$,

$$
\begin{aligned}
& \mathrm{S}=\mathrm{r} / \mathrm{r}_{\mathrm{f}}, \\
& \mathrm{A}=\left(\mathrm{h}^{2}+\mathrm{S}^{2}+1\right) /(2 \mathrm{~S}), \text { and } \\
& \mathrm{B}=\left(1+\mathrm{S}^{2}\right) /(2 \mathrm{~S})
\end{aligned}
$$

The maximum view factor is the vectorial sum of the horizontal and vertical view factors

$$
F_{m}=\sqrt{ }\left(F_{B}^{2}+F_{V}^{2}\right)
$$

However, for most cases of interest here, the horizontal view factor alone is used.

Rein et. al. [20] present graphs of view factors versus distance to target for cylinders tilted at various angles. The graphs were developed by numerically integrating equation (17). Mudan [21] presents an analytical solution to equation (17) for tilted cylinders based on work presented in reference [18]. A number of errors, presumably typographical, were found in the equations presented in reference [21]. Since the original source document [18] could not be obtained in the limited amount of time available for completion of this study, a numerical approach was used to calculate the tilted cylinder view factors. In the numerical approach, view factors are determined by dividing the cylinder into a number of incremental rectangular areas and summing the view factors for each of these small elemental areas. 
The view factors for both vertical and tilted cylinder geometries approach similar values at large distances from the fire. As a check, view factors for vertical cylinders to targets oriented perpendicular to the ground were calculated using both the analytical solution and the numerical method. The results agreed to within one percent.

\subsection{Computer Program for Calculating Radiation Heat Flux}

In an effort to facilitate the computation of radiation heat flux values, the methodology described in the preceding sections was coded into a user-interactive computer program. The FORTRAN 77 source code is contained in Appendix $B$ of this report. The program requires input data describing the fuel, the source and target geometries, and the wind speed. Specifically, the density of the fuel vapors and its heat of combustion must be specified. The fuel flow rate and the diameter of the fire area must also be provided. The height of the target and its angle of tilt relative to the ground are required. The flame emissivity, the transmissivity of the atmosphere, and the fraction of the fire energy release rate that is released as radiation are assumed to have values of 1 . These values may be altered by the user, if desired. The program will calculate the radiation heat flux at any distance (up to a user-specified maximum) from the fire source for each user-specified wind speed (including no wind). The flame length, its angle of inclination, and the configuration factor are calculated for each wind speed. The computer program presented in the Appendix B was used to generate figures 7 through 11. 


\section{ANALYSIS OF 19F4 TRAINER RADIATION EFFECTS}

The previously discussed results for flame geometry and configuration factors together with equation (6) were used to calculate the radiation flux values at various distances from the flame. In particular, the radiation flux to the instructor's tower and the crane were determined. The properties of propane and air used in this analysis are summarized in Tables 1 and 2, respectively.

In order to develop estimates of potential damage, the radiation heat flux levels produced during operation of the $19 F 4$ must be related to those levels determined to cause structural damage and human injury. The radiation flux at which unprotected humans begin to feel pain is about $600 \mathrm{Btu} / \mathrm{hr} \mathrm{ft}^{2}$ $[5,22]$. Skin burns have been determined to occur at flux levels at or above $1500 \mathrm{Btu} / \mathrm{hr} \mathrm{ft}^{2}[4,5]$. The threshold flux for equipment damage varies widely. In addition to the flux intensity, the minimum potentially damaging flux level strongly depends on the duration of the flux and the size (mass) of the structure. The ignition of wood, both piloted and spontaneous, has been the subject of extensive research. The radiation flux at which ordinary combustibles such as wood, paper, etc. will spontaneously ignite is estimated to be approximately $10000 \mathrm{Btu} / \mathrm{hr} \mathrm{ft}^{2}$ [4,5,23]. Piloted ignition of wood has been determined to occur at radiation heat flux levels as low as $4500 \mathrm{Btu} / \mathrm{hr}$ $\mathrm{ft}^{2}[5,24]$. Reference [25] recommends a maximum allowable radiation heat flux exposure for equipment of $3000 \mathrm{Btu} / \mathrm{hr} \mathrm{ft}^{2}$. 
Figure 7 presents results showing the flame length extension due to wind effects. The calculations presented in figures 7, 8, and 9 are based on a cylindrical flame shape with a diameter of $52 \mathrm{ft}$ and a height of $12 \mathrm{ft}$. Initially at lower wind speeds, the flame length increases due to the "stretching" effect produced as the wind passes over the flame. At moderate wind speeds, the flame length will decrease below its value for the no-wind condition (12 ft). This phenomena has been observed experimentally by Thomas [8]. He suggests that the flame length decrease may result from locally improved mixing and better combustion efficiency. The variation of the flame angle of tilt with increasing wind speed is shown in figure 8 . As the wind speed increases, the flame bends more and more away from the wind. Figure 9 shows the variation of the height of the flame tip above the deck with wind speed. This value is calculated by multiplying the flame length by the sine of its angle of inclination at any given wind speed.

The variation of the radiation flux with distance from the centerline of the flame due to wind effects is shown in figures 10 and 11 . Again, the results presented in figures 10 and 11 are based on a cylindrical geometry with a diameter of $52 \mathrm{ft}$ and a height of $12 \mathrm{ft}$. The radiation flux values presented are appropriate for use in estimating the potential hazard to targets located at least $26 \mathrm{ft}$ away from the burner centerline. The results presented in these figures assume that 100 percent of the energy produced by the fire is radiated. This would correspond to assuming $\chi$ in equation (6) is equal to one. For propane flowing at the rate of $27.5 \mathrm{ft}^{3} / \mathrm{s}$, the total energy released at any given time is $60390 \mathrm{Btu} / \mathrm{s}$. 
In actual practice as described earlier, the amount of energy radiated by flames will vary depending on the test conditions (smoke blockage, fuel type, etc.). Usually, it will be substantially less than 100 percent. To adjust figures 10 and 11 for a $\chi$ value other than one, simply multiply the heat flux scale (vertical scale) by the assumed $\chi$ value. Regardless of the assumed radiation fraction, the general trend of the results will be the same.

As the wind speed increases, the radiation flux at distances close to the fire increases. At some point (approximately $45 \mathrm{ft}$ from the centerline of the fire in this analysis), this trend reverses. Increasing wind speed decreases the radiation flux. At distances less than about $45 \mathrm{ft}$ from the burner centerline, the maximum radiation flux is obtained at a wind speed of about $5 \mathrm{mph}$. At wind speeds above $5 \mathrm{mph}$, the calculated radiation flux begins to decrease. Eventually, the wind influenced radiation flux values fall below the corresponding no wind values.

Initially at low wind speeds, the flame bends and its length increases. This increases the view factor and results in higher radiation flux values. As the wind speed increases, the flames continue to bend; however, they also shorten. While this does place the flame tip closer to a particular target, it decreases the projected area of the flame as viewed from the target. This in turn decreases the amount of radiation received by the target object. The Navy fire fighter training facilities will be located in several regions of the country. The influence of the wind speed and direction on the radiation flux levels produced is very important. The layout of each training facility must be based on an analysis of the prevailing conditions in the area in which 
it is located. A generic site layout valid for all locations cannot and should not be provided.

The instructor's tower will be located approximately $80 \mathrm{ft}$ from the burner centerline (50 ft $(15.2 \mathrm{~m})$ from the edge). At this location and assuming a value of 0.4 (40 percent) for $\chi$, the radiation flux, from figure 11 , is between 700 and $2200 \mathrm{Btu} / \mathrm{hr} \mathrm{ft}\left(0.4 \times 5500 \mathrm{Btu} / \mathrm{hr} \mathrm{ft}^{2}\right.$ for $5 \mathrm{mph}$ wind condition) depending on the wind speed. According to references [2] and [3], forty percent radiation was the maximum amount measured for propane flames. It is interesting to note that wind speeds, in the direction of the instructor's tower in excess of $25 \mathrm{mph}$, keep the radiation flux below 1200 $\mathrm{Btu} / \mathrm{hr} \mathrm{ft}^{2}$. This phenomena reflects the importance of configuration factors. As the wind speed increases, the instructor's tower is able to "see" less of the flame surface. The flux levels at wind speeds less than $25 \mathrm{mph}$ are at or above the pain threshold and would be dangerous for unprotected humans. The effects on buildings and other structures may also be significant.

Current Navy specifications [1] would place the crane shield $22.5 \mathrm{ft}$ away from the burner centerline or $4.5 \mathrm{ft}$ from the edge of the fireplace (figure 2). In turn, the crane centerline would be $3 \mathrm{ft}$ from the radiation shield. Using the cylindrical radiator assumption with a diameter equal to either the longest dimension or the equivalent circle diameter locates the crane shield within the fire area. In this case, the parallelpiped shape would be a more appropriate representation of the flame to target (the crane and its shield) geometry. If the fire area is assumed to have a rectangular base with dimensions of $52 \mathrm{ft}$ by $36 \mathrm{ft}$ and the flames are $12 \mathrm{ft}$ high, the heat 
flux reaching the crane shield would be approximately $19000 \mathrm{Btu} / \mathrm{hr} \mathrm{ft}^{2}$ assuming the fire radiates 40 percent of its total energy release. This flux is over six times the maximum amount recommended for equipment exposure [25]. The radiation enhancement produced by the wind will be an even more important consideration in the development of protection for the crane. When the wind is blowing in the direction of the crane and shield, it may force the flame into contact with the crane shield. This will greatly increase the thermal exposure to the crane shield and ultimately to the crane itself.

\section{SUMMARY}

Most of the results from this analysis of the radiation effects of the $19 F 4$ have been presented in the form of graphs. These graphs may be used to determine the radiation fluxes at locations and for conditions not explicitly mentioned in this study. The target objects of primary concern are the instructor's tower and the facility crane. The analysis (assuming $x=0.4$ ) indicates that the instructor's tower will be exposed to a radiation flux of between 700 and $2200 \mathrm{Btu} / \mathrm{hr} \mathrm{ft}^{2}$. The crane radiation shield could receive a radiation flux in excess of $19000 \mathrm{Btu} / \mathrm{hr} \mathrm{ft}^{2}$. In fact, the hot gases of the flame may impinge on the crane shield, increasing the heat transfer and the resulting total heat flux to the crane.

The specifications [1] for the design of the 19F4 trainer state that the trainer shall not be operated when the prevailing winds are in the direction of the crane. Even in the presence of no wind, the crane radiation shield 
will be subjected to a substantial radiation heat flux. The resulting effect on the crane itself will depend on the effectiveness of the crane shield.

This radiation shield must be capable of withstanding large radiation heat fluxes and direct flame impingement. If possible, the trainer should only be operated when there is a wind blowing away from the crane. In addition, the instructor's tower should be located in the same general direction as the crane. When the wind is blowing away from the crane, it will also be blowing away from the instructor's tower. This will minimize the radiation fluxes to both structures.

\section{REFERENCES}

[1] Firefighting School Facilities Criteria 21C12 \& 19F Series Devices, Department of the Navy, Atlantic Division, Naval Facilities Engineering Command, Norfolk, Virginia 23511, March 1987.

[2] Markstein, G.H., Radiative Energy Transfer from Turbulent Diffusion Flames, Combustion and Flame, 27, pp. 51 - 63, 1976.

[3] Hägglund, B. and Persson, L., The Heat Radiation from Petroleum Fires, FOA Report, Forsvarets Forskningsanstalt, Stockholm, 1976.

[4] American Gas Association, LNG Safety Research Program, Report IS 3-1, 1974.

[5] DiNenno, P.J., Simplified Radiation Heat Transfer Calculations from Large Open Hydrocarbon Fires, SFPE Technology Report 82-9, Society of Fire Protection Engineers, Boston, Massachusetts, 1982.

[6] Orloff, L., Simplified Radiation Modeling of Pool Fires, 18th Symposium (Internationa1) on Combustion, pp. 549 - 561, 1981.

[7] Hall, A.R., Oxidation and Combustion Review, 6, pp. $169-225,1973$.

[8] Thomas, P.H., The Size of Flames from Natural Fires, 9 th Symposium (International) on Combustion, pp. 844 - 859, 1963. 
[9] Heskestad, G., Luminous heights of turbulent diffusion flames, Fire Safety Journal, 5, pp. 103 - 108, 1983.

[10] Cox, G. and Chitty, R., Combustion and Flame, 60 p. 219, 1985.

[11] Hasemi, Y. and Tokunaga, T., Fire Safety Science and Technology, 4 p. 15,1984

[12] Steward, F.R., Combustion Science and Technology, 2, p. 203, 1970.

[13] Cetegen, B.M., Zukoski, E.E., and Kubota, T., Entrainment and Flame Geometry of Fire Plumes, NBS-GCR-82-402, U.S. Department of Commerce, National Bureau of Standards, Washington, D.C. 20234, 1982.

[14] Beyler, C.L., Fire Plumes and Ceiling Jets, Fire Safety Journal, 11, pp. $53-75,1986$.

[15] Zukoski, E.E., Kubota, T., and Cetegen, B., Entrainment in the Near Field of a Fire Plume, NBS-GCR-81-346, U.S. Department of Commerce, National Bureau of Standards, Washington, D.C. 20234, 1981.

[16] Corlett, R.C., Velocity distributions in fires in Heat Transfer in Fires, P.L. Blackshear (ed.), John Wiley and Sons, New York, pp. 239 255,1974 .

[17] Welker, J.R. and Sliepcevich, C.M., Bending of wind blown flames from liquid pools, Fire Technology, 2, p. 127, 1966.

[18] Raj, P.K. and Kalelkar, A.S., Assessment Models in Support of the Hazard Assessment Handbook (CG-466-3), Chap. 9, Technical Report prepared for the U.S. Coast Guard, NTIS publication \#AD776617, January 1974.

[19] Sparrow, E.M., Radiant interchange between surfaces separated by nonabsorbing and nonemitting media in Handbook of Heat Transfer, W.M: Rohsenow and J.P. Hartnett (eds.), McGraw-Hill Book Company, New York, 1973.

[20] Rein, R.G., Sliepcevich, C.M., and Welker, J.R., Radiation view factors for tilted cylinders, Journal of Fire and Flammability, 1, p. 140, 1970.

[21] Mudan, K.S., Thermal Radiation Hazards from Hydrocarbon Pool Fires, Proc. Energy Combustion Sci., Vol. 10, pp. 59-80, 1984.

[22] Atallah, S. and Allan, D.S., Safe separation distances from liquid fuel fires, Fire Technology, 7 (1), pp. 47 - 56, 1971.

[23] Lawson, D.I., Fire and the atomic bomb, Fire Research Bulletin No. 1, Her Majesty's Stationary Office, London, England, 1954.

[24] Drysdale, D., An Introduction to Fire Dynamics, John Wiley \& Sons Ltd., New York, p. 67, 1985. 
[25] Tan, S.H., Flare system design simplified, Hydrocarbon Processing, 46, pp. 172 - 176, 1967. 
TABLE 1. Properties of Propane

$$
\begin{aligned}
\Delta \mathrm{H}_{\mathrm{c}} & =20000 \mathrm{Btu} / 1 \mathrm{~b}_{\mathrm{m}} \\
\rho_{\mathrm{v}} & =0.1098 \mathrm{Ib}_{\mathrm{m}} / \mathrm{ft}^{3}
\end{aligned}
$$

TABLE 2. Properties of Ambient Air

$$
\begin{aligned}
& \mathrm{k}=0.015 \mathrm{Btu} / \mathrm{hr} \mathrm{ft}{ }^{\circ} \mathrm{F} \\
& \mathrm{c}_{\mathrm{p}}=0.24 \mathrm{Btu} / 1 \mathrm{~b}_{\mathrm{m}}{ }^{\circ} \mathrm{F} \\
& \rho_{\mathrm{a}}=0.068671 \mathrm{~b}_{\mathrm{m}} / \mathrm{ft}^{3} \\
& \nu_{\mathrm{a}}=1.6878 \times 10^{-4} \mathrm{ft}^{2} / \mathrm{s}
\end{aligned}
$$




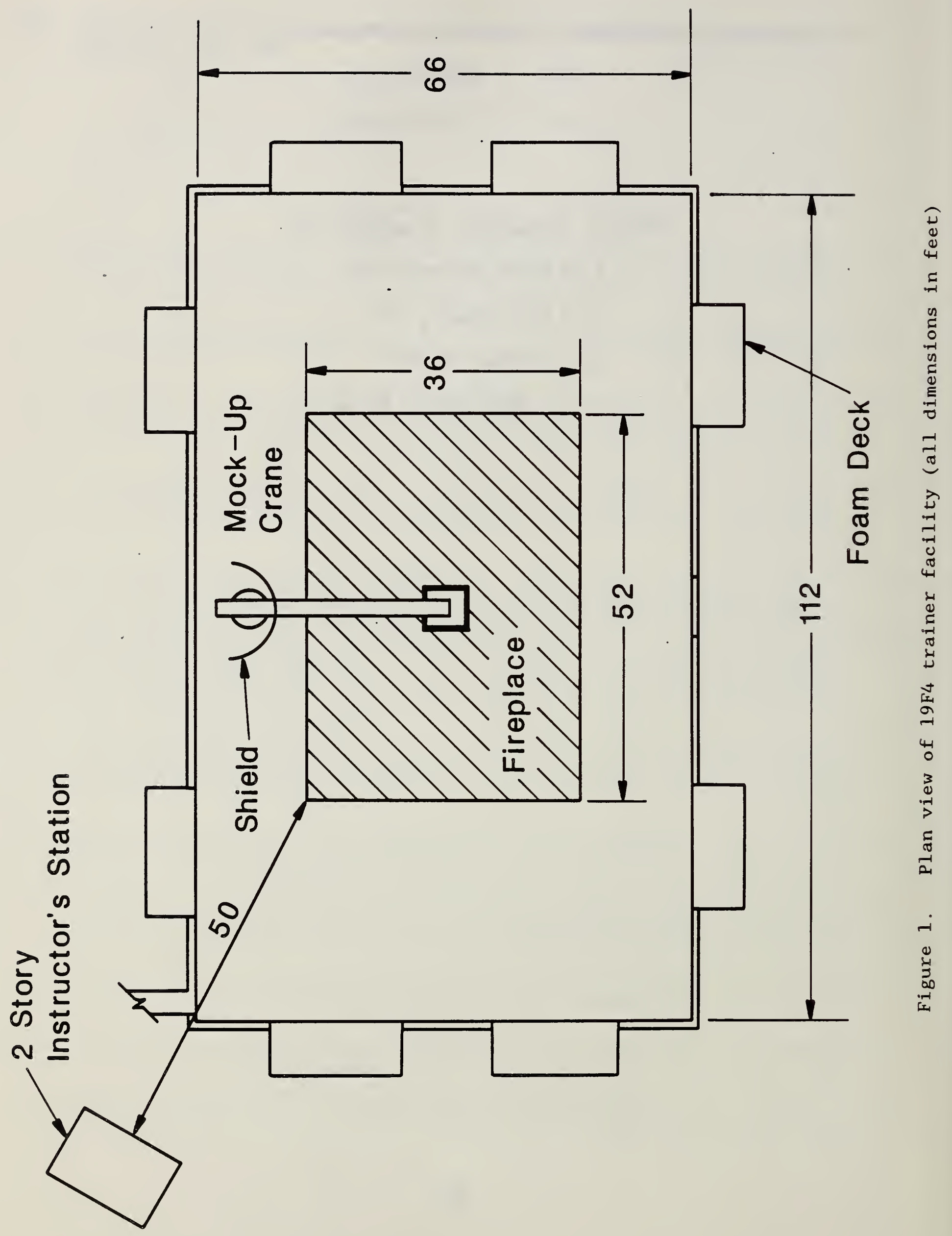




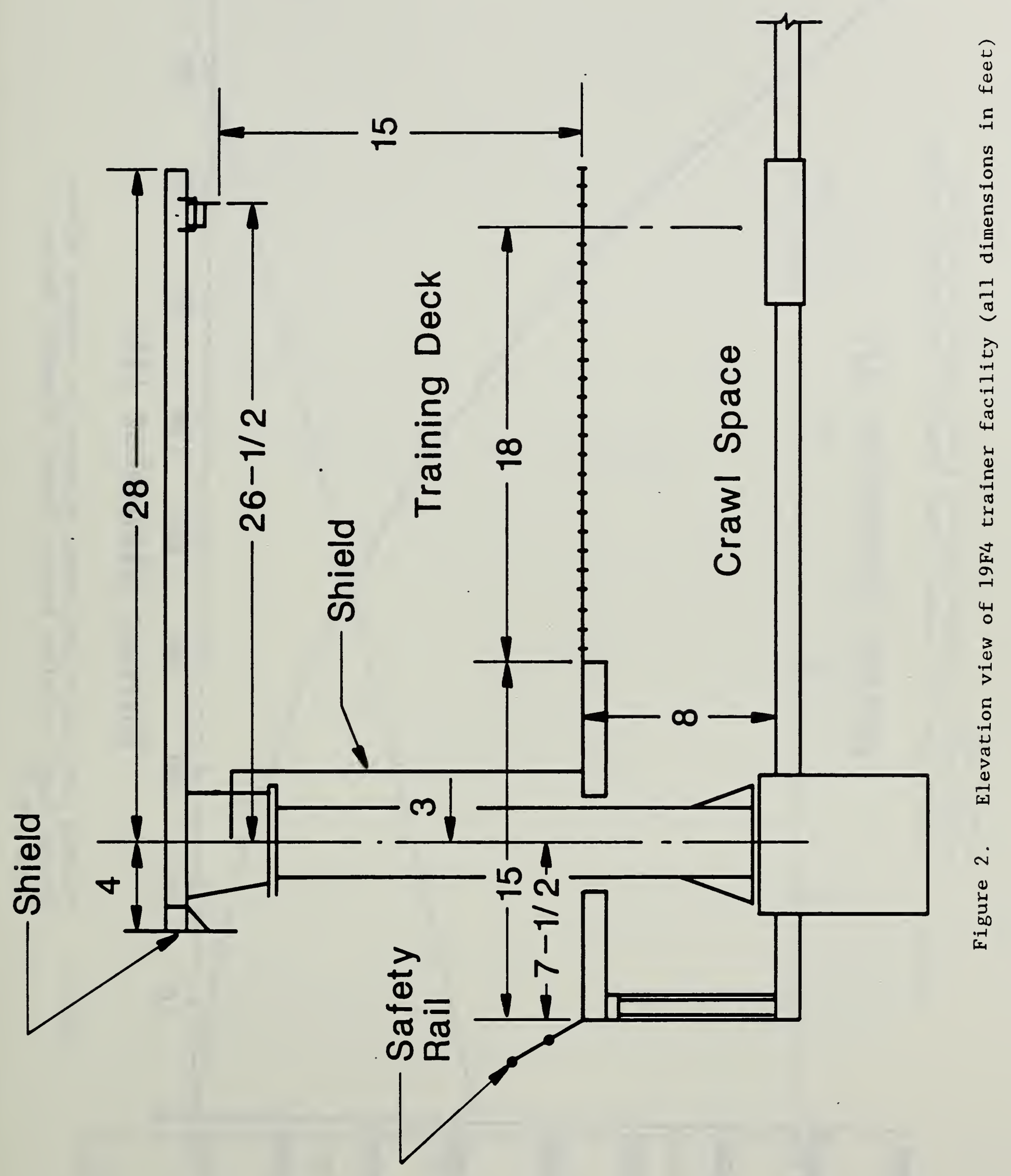




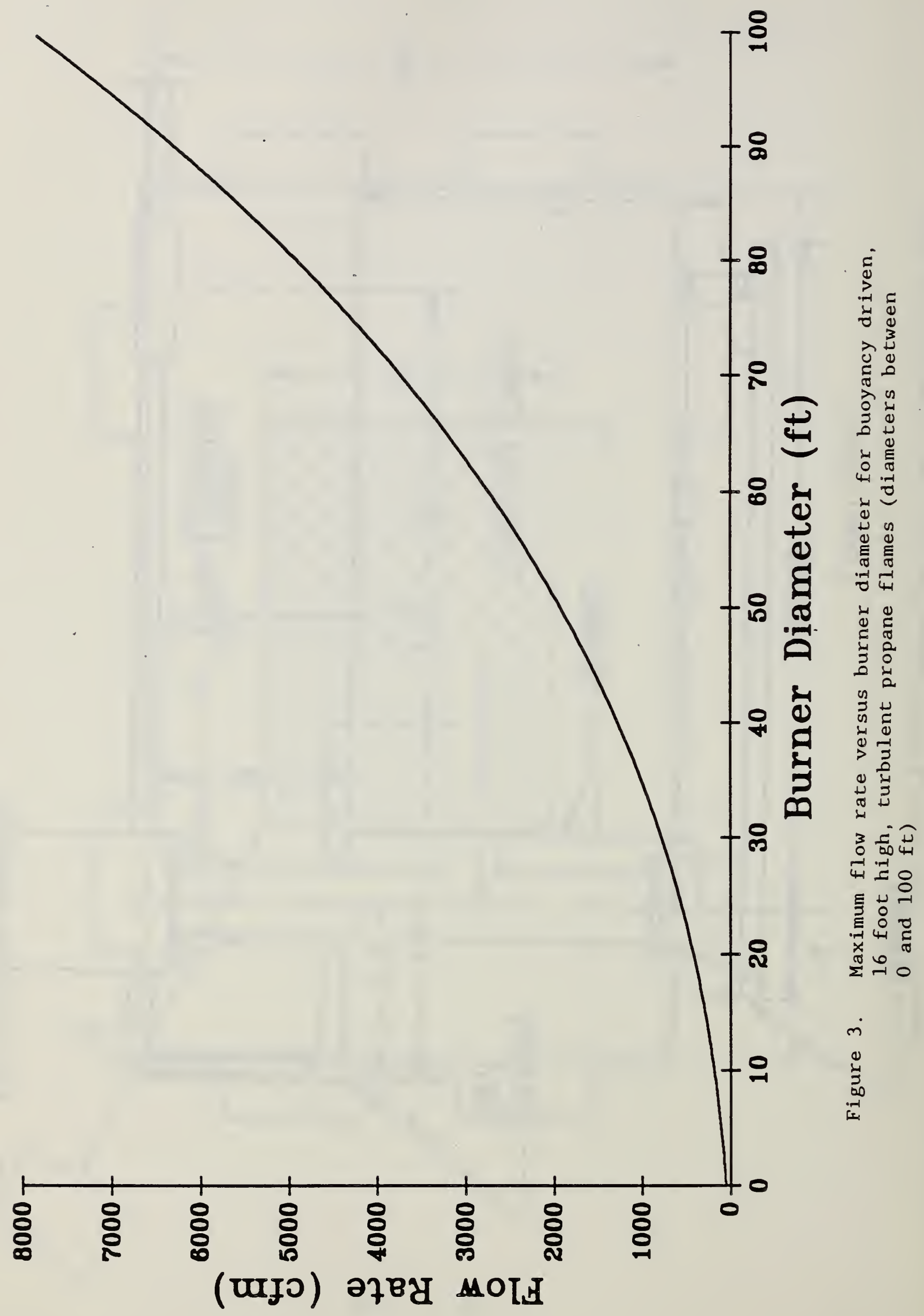




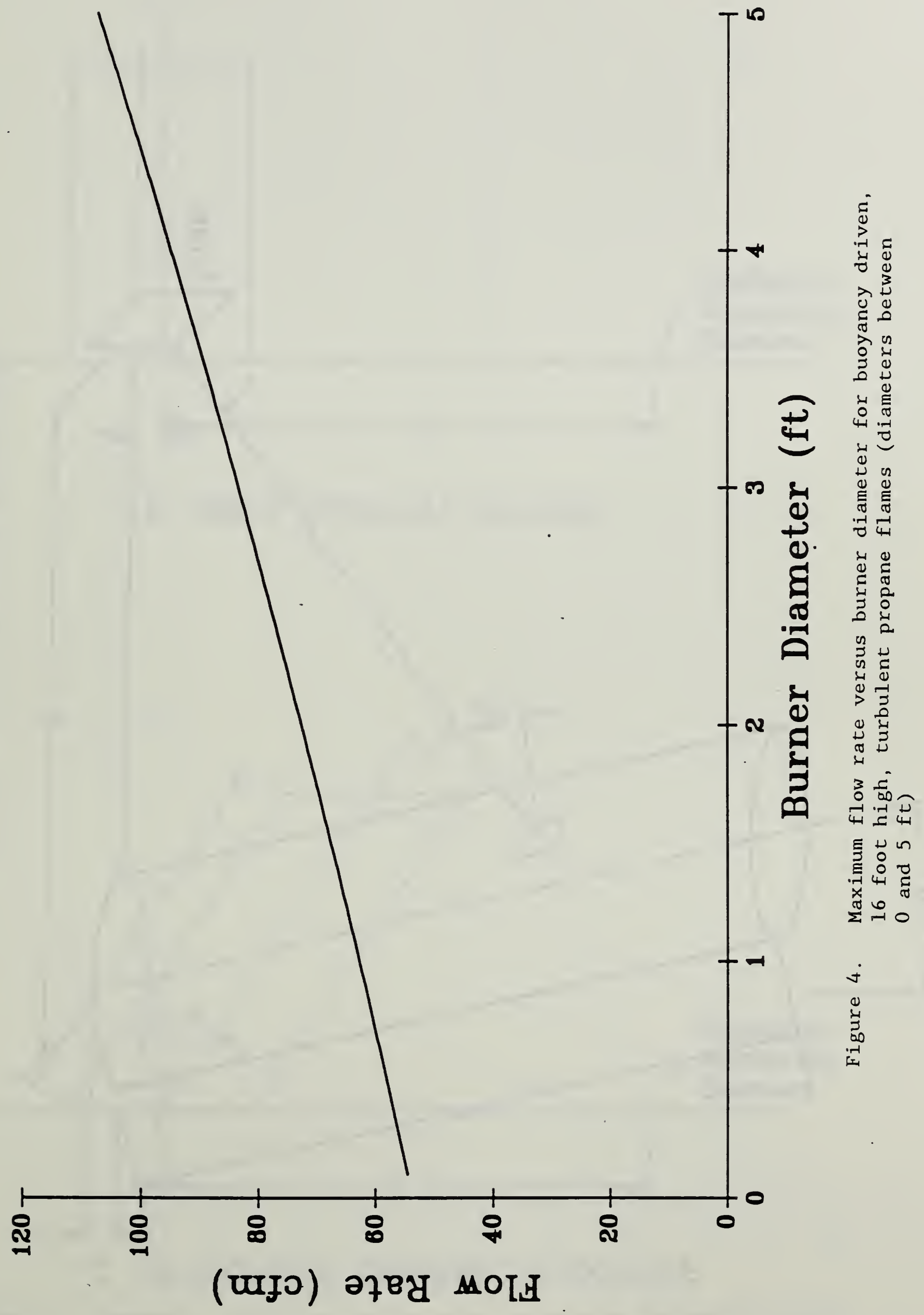




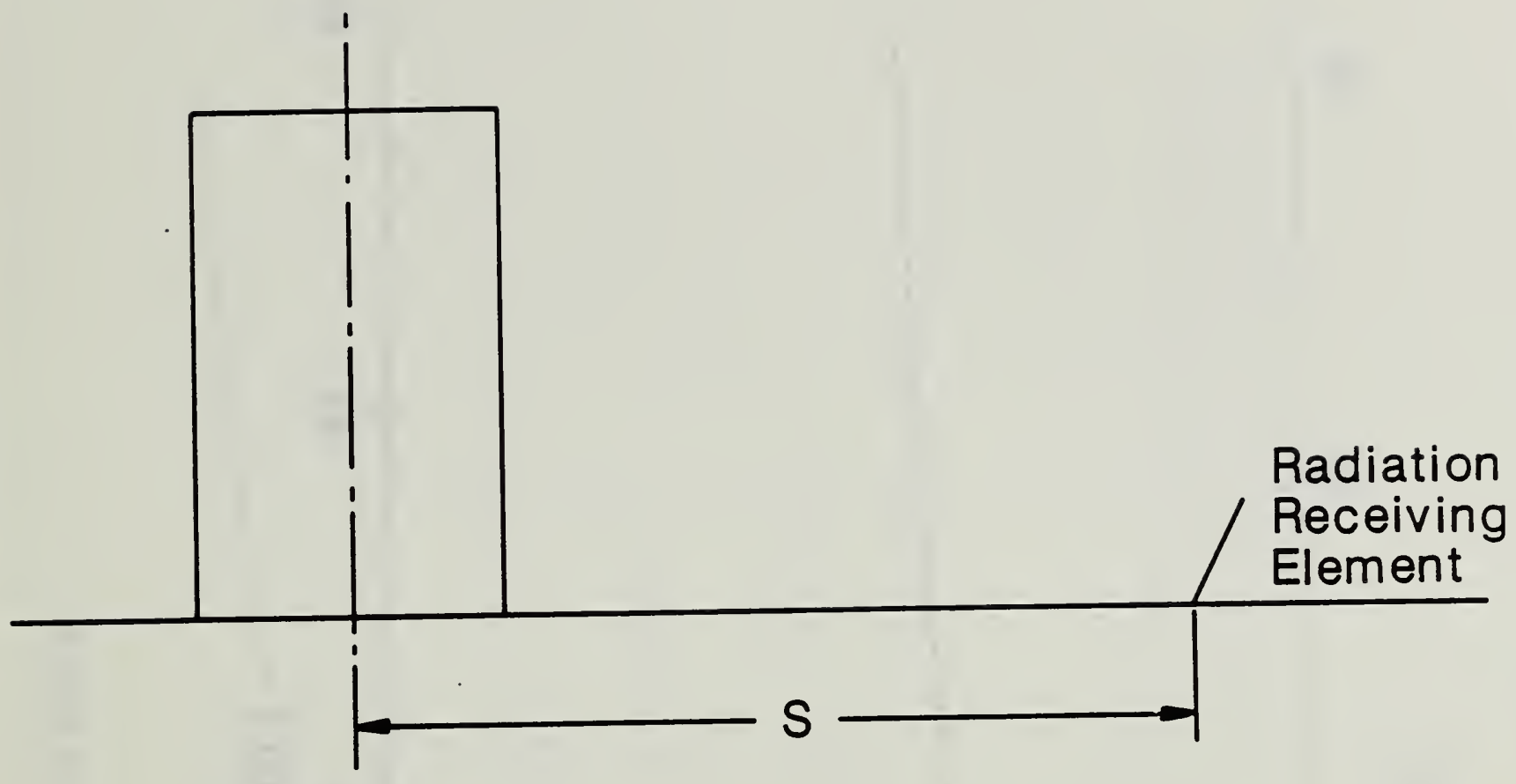

(a) RIGHT CIRCULAR SOURCE

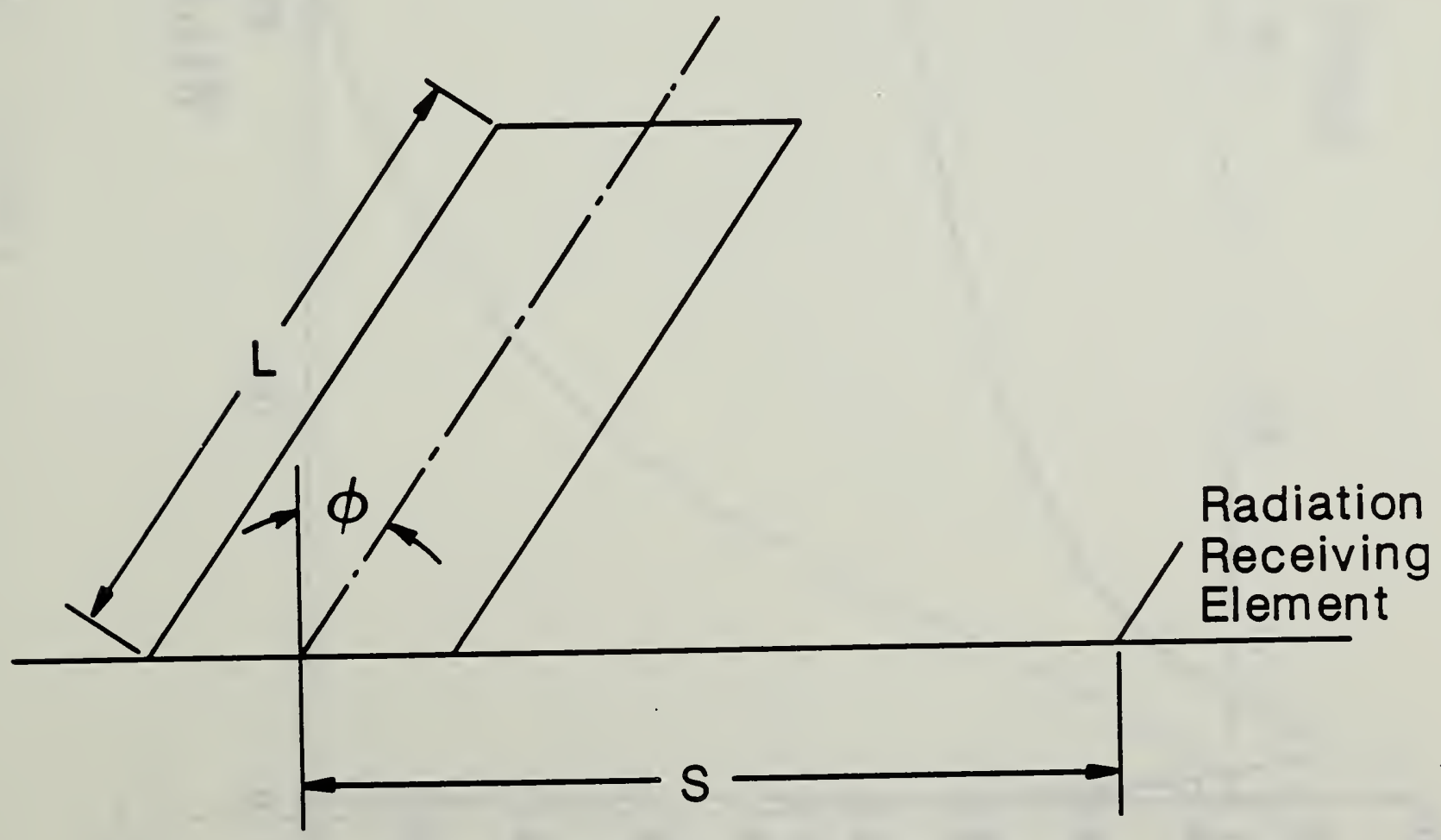

(b) INCLINED CYLINDRICAL SOURCE

Figure 6. Geometric configuration for calculating view factors for right circular and inclined cylindrical sources 


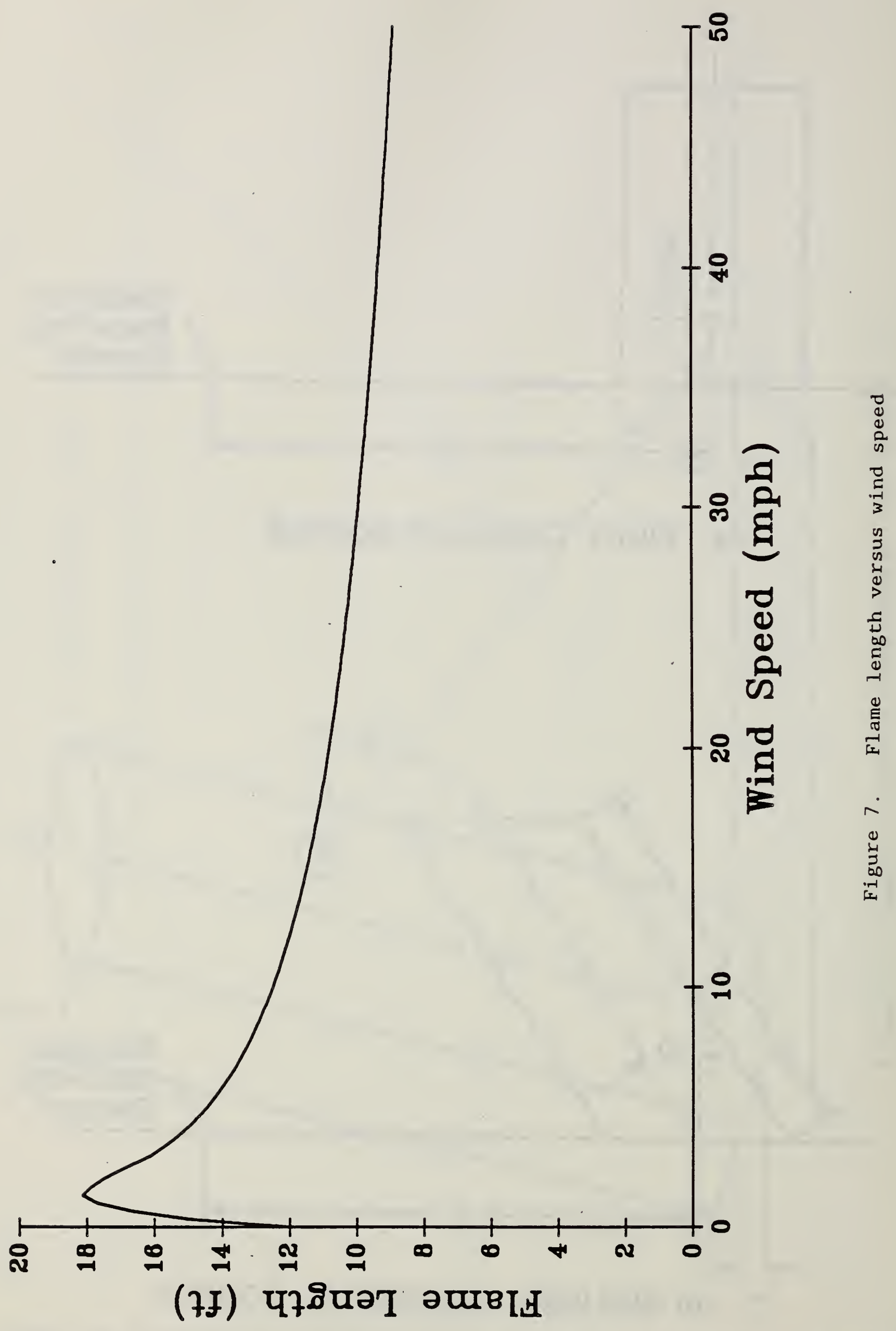




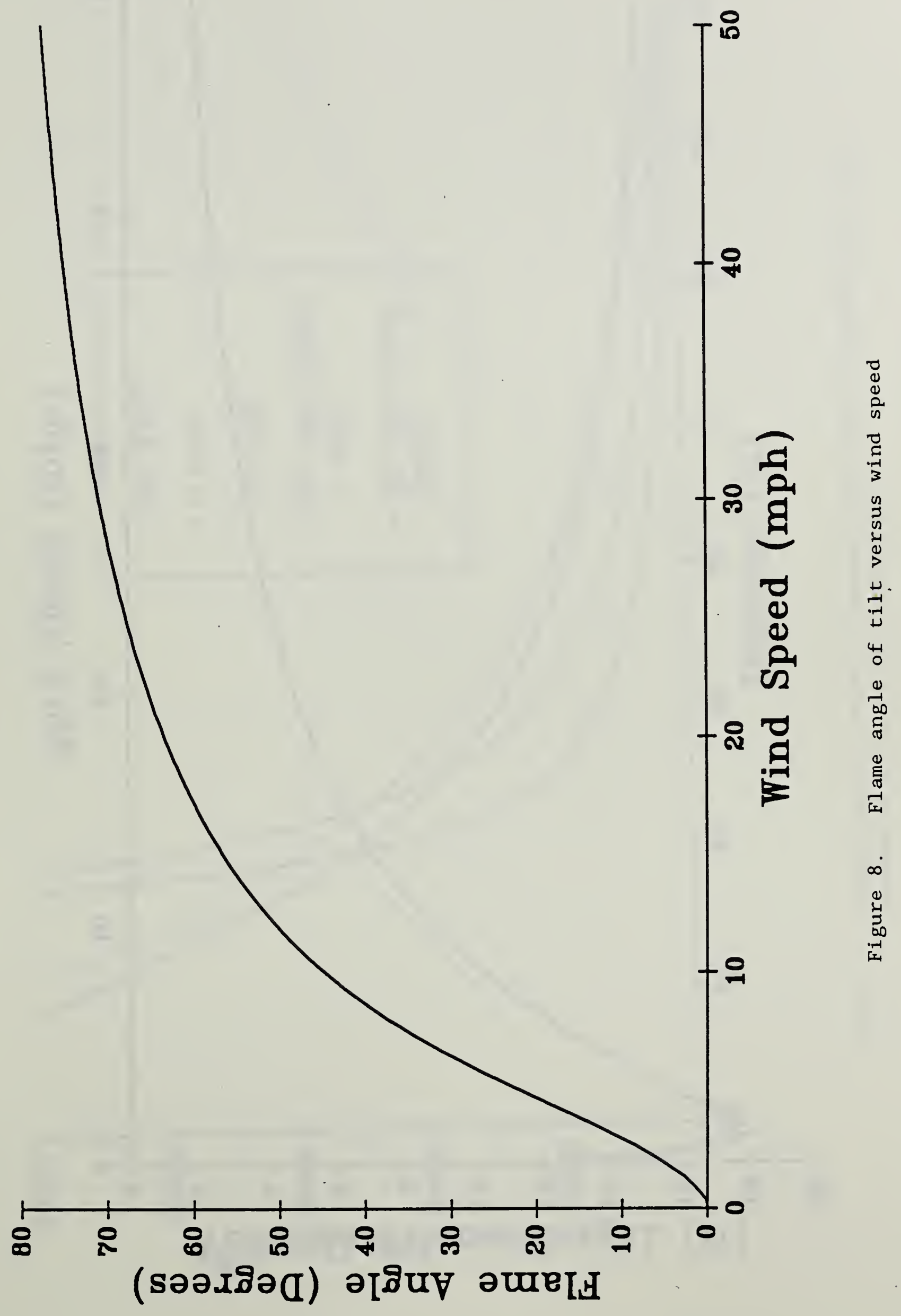




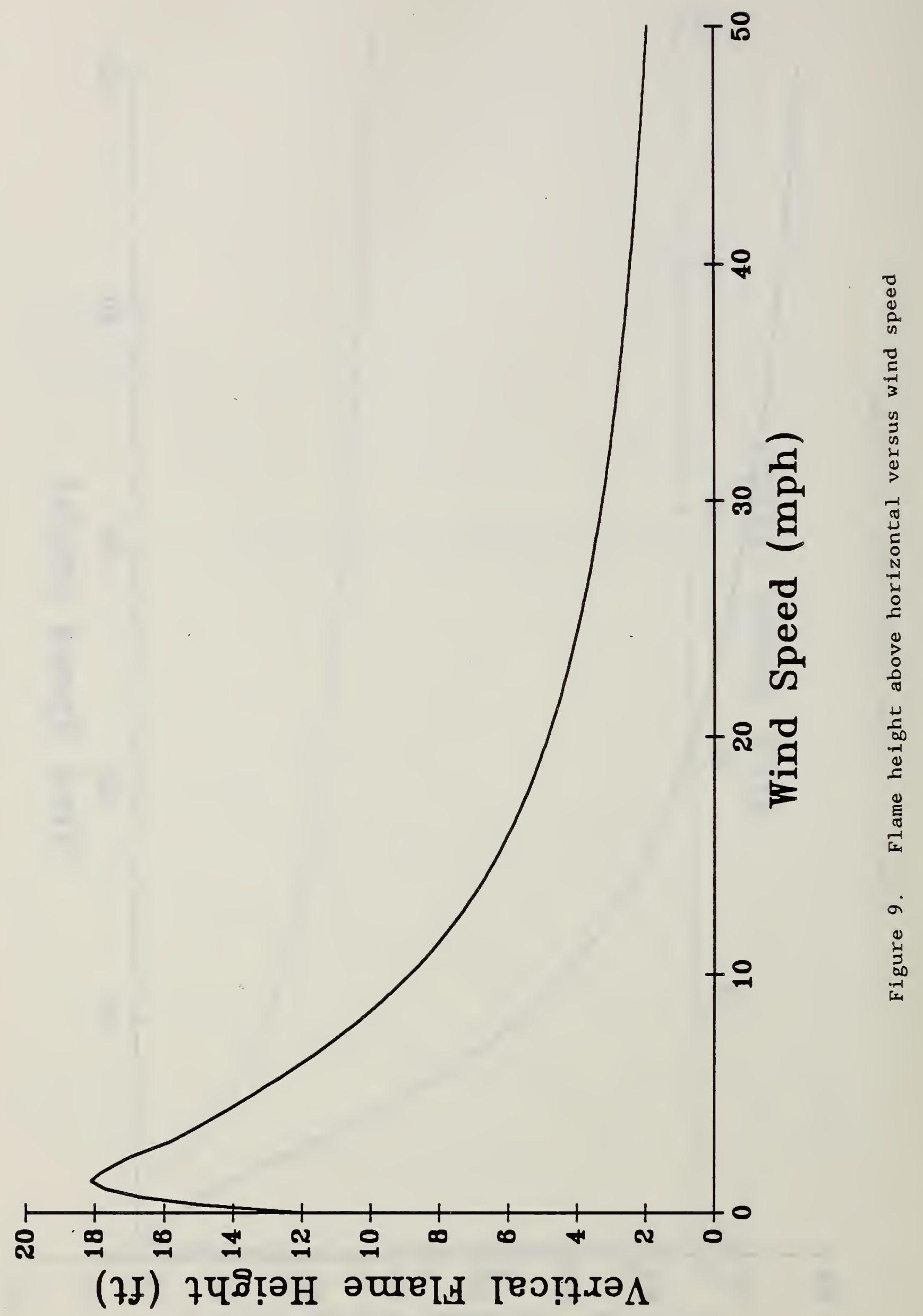




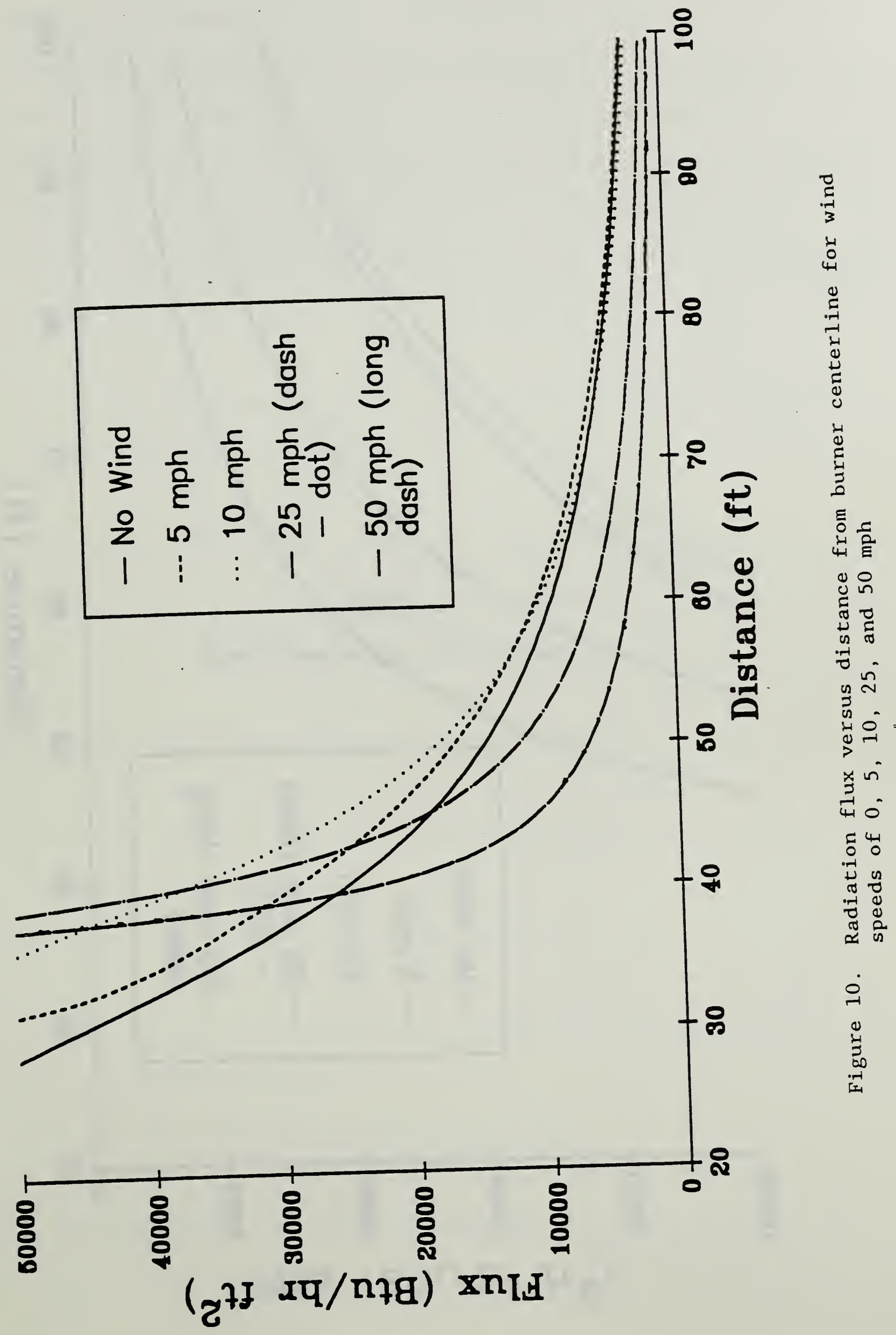




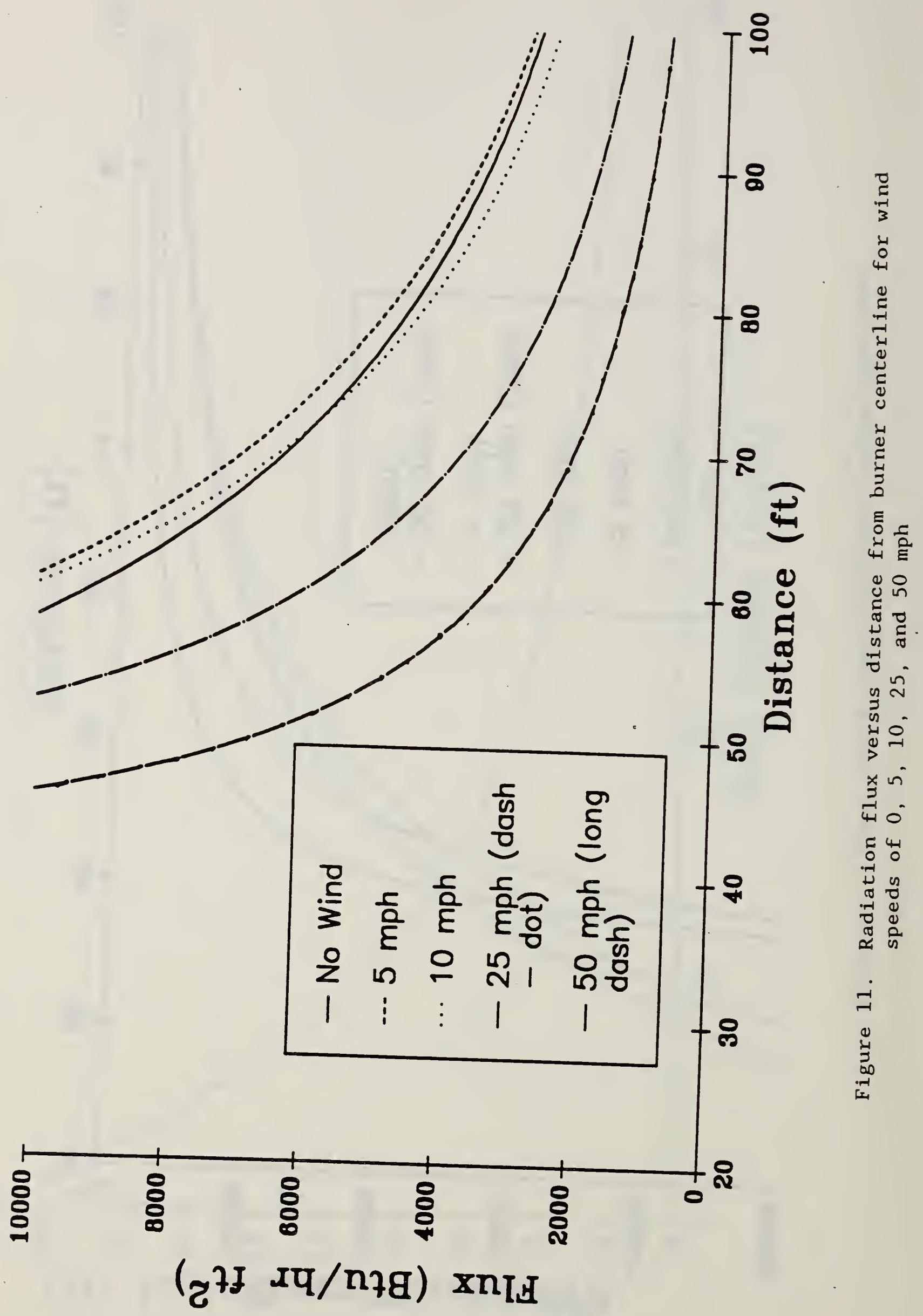


APPENDIX A

Flame Temperature Calculations 
As part of an effort to validate the use of equation (6) for estimating radiation heat fluxes to targets, a modified form of the equation was used to calculate radiation flame temperatures. The flame temperatures, calculated using equation ( 8 ), were compared to data obtained by researchers using propane and PMMA fuels. Specifically, radiation flame temperatures were calculated for and compared to data obtained by Orloff [1] ${ }^{1}$ from studies of flames generated by burning PMMA.

The general form of the equation used to estimate flame temperature is

$$
\mathrm{T}_{\mathrm{f}}=\left[\frac{\chi \Delta \mathrm{H}_{\mathrm{c}} \dot{\mathrm{m}}^{\prime \prime} \mathrm{A}_{\text {fire }}}{\epsilon \sigma \mathrm{A}_{\mathrm{flame} \text { surface }}}\right]^{1 / 4}
$$

where $\dot{\mathrm{m}}^{\prime \prime}$

$\Delta \mathrm{H}_{\mathrm{c}}$

$\epsilon$

$\sigma$

$x$

$A_{\text {fire }}$

Aflame surface - the surface area of the flame envelope.
- mass burning rate per unit area of the fire source,

- the heat of combustion of the fuel,

- emissivity of the flame,

- Stefan-Boltzmann constant (1.71 x 10-9 Btu/hr $\left.f t^{2} R^{4}\right)$,

- the fraction of the fire's energy which is radiated,

- the area of the base of the fire, and this appendix. 
For the analysis of Orloff's data [1], the PMMA flames are assumed to have a conical shape. The equations for the area of the base of a cone, the surface area of a cone, and the volume of a cone, respectively are:

$$
\begin{gathered}
A_{b a s e}=(1 / 4) \pi d^{2} \\
A_{\text {surface }}=(1 / 2) \pi d \sqrt{ }(1 / 4) d^{2}+L^{2} \\
V=(1 / 12) \pi L d^{2}
\end{gathered}
$$

where $d$ - diameter of the base of the cone and

L - height of the cone (flames).

The PMMA flames studied by Orloff were not optically thick and did not represent black bodies. The assumption of unity for emissivity, $\epsilon$, (used throughout the rest of this paper) would lead to gross errors in the calculated flame temperatures. Therefore, the first step in calculating flame temperatures is to calculate the effective emissivity of Orloff's PMMA flames. The emissivity can be expressed in terms of a gray absorption-emission coefficient, $k$, and the flame geometry. Orloff [1] provides the following equation for estimating flame emissivity

$$
\epsilon=1-\exp \left(-\eta k V_{f} / A_{p}\right)
$$

where $\eta$ - an adjustable parameter,

k - the gray absorption-emission coefficient,

$V_{f}$ - the radiating gas volume, and

$A_{p}$ - the projected area of the flames. 
As part of his analysis, Orloff determined an average absorption-emission coefficient, $\bar{k}_{f}$, for his PMMA flames. This average value of $0.47 \mathrm{ft}^{-1}$ will be used for the $k$ in equation (A-5). Orloff recommends a value of 0.95 for $\eta$ (the adjustable parameter). The projected area, $A_{p}$, refers to the effective area that is "seen" by the target. For a target viewing flames with a conical shape, the projected area would be an isosceles triangle with a base width equal to the diameter of the fire area and a height equal to the flame height. In equation form, this is

$$
A_{p}=(1 / 2) d L
$$

Using equation (A-4) for the radiating gas volume together with equation (A-6) yields the following ratio of flame volume to projected area

$$
\mathrm{V}_{\mathrm{f}} / \mathrm{A}_{\mathrm{p}}=\pi \mathrm{d} / 6
$$

From Orloff's data [1], the diameter of the burning area used for a number of tests was $1.25 \mathrm{ft}$. The effective flame emissivity is, from equation (A-5), equal to 0.25 . This emissivity value agrees reasonable well with a value of 0.26 quoted by de Ris [2] for PMMA flames.

The next step in calculating radiation flame temperatures is evaluating the flame base area, $A_{f i r e}$, to flame surface area, $A_{f l a m e}$ surface, ratio. In this analysis which assumes the flames have a cone-like shape, the flame surface area is equal to the surface area of a cone (equation (A-3)) plus the area of the cone base (equation (A-2)). The flame base area is equal to the 
area of the base of the cone (equation (A-2)). From Orloff's data [1], the average flame height appears to be about three times the burner radius or three-halves times the burner diameter. The ratio of flame base area to flame surface area is $(\sqrt{10}-1) / 9$. Also from Orloff's data [1], the heat of combustion for PMMA is $11590 \mathrm{Btu} / 1 \mathrm{~b}_{\mathrm{m}}$.

Equation (A-1) may be re-written in the following form:

$$
\mathrm{T}_{\mathrm{f}}=\left[\frac{\Delta \mathrm{H}_{\mathrm{c}} \mathrm{A}_{\text {fire }}}{\epsilon \sigma \mathrm{A}_{\text {flame surface }}}\right]^{1 / 4}\left[\chi \dot{\mathrm{m}}^{\prime \prime}\right]^{1 / 4}
$$

Substituting the available data into equation (A-8) yields

$$
\mathrm{T}_{\mathrm{f}}=12374.6(x \dot{\mathrm{m}})^{1 / 4}
$$

Equation (A-9) will be used to calculate the flame temperature for PMMA flames at various burning rates.

By changing the distance between the fuel surface and the container lip, Orloff was able to vary the PMMA burning rate while maintaining the same burner diameter. The burning rate ranged from a low of $0.002 \mathrm{lb}_{\mathrm{m}} / \mathrm{ft}^{2} \mathrm{~s}$ at a zero surface to lip distance to a maximum of about $0.00361 b_{m} / \mathrm{ft}^{2} \mathrm{~s}$ for a surface to lip distance of 2 in. There was a slight decrease in burning rate as the surface to lip distance increased above $2.4 \mathrm{in}$. Orloff estimated the radiation fraction, $\chi$, to be from 0.32 at the zero distance to 0.42 for the 3 
in. distance. The radiation flame temperatures calculated using equation (A-

9) and Orloff's data are summarized below

\begin{tabular}{|c|c|c|c|}
\hline $\begin{array}{c}\text { Lip Size } \\
\text { (in.) }\end{array}$ & $\begin{array}{c}\text { Burning Rate } \\
\left(1 \mathrm{~b}_{\mathrm{m}} / \mathrm{ft} \mathrm{t}^{2} \mathrm{~s}\right)\end{array}$ & $\chi$ & $\begin{array}{c}\text { Flame Temperature } \\
\text { (R) }\end{array}$ \\
\hline 0 & 0.0020 & 0.32 & 1968 \\
\hline 0.49 & 0.0030 & 0.37 & 2259 \\
\hline 1.95 & 0.0036 & 0.40 & 2411 \\
\hline
\end{tabular}

These values differ from Orloff's average radiation flame temperature of $2270 \mathrm{R}$ by a maximum of about 13 percent. Given the gross assumptions made in order to complete this analysis, this is very good agreement.

\section{$\underline{\text { References }}$}

[1] Orloff, L., Simplified Radiation Modeling of Pool Fires, 18th Symposium (Internationa1) on Combustion, pp. 549 - 561, 1981.

[2] de Ris, J., "Fire Radiation - A Review," Factory Mutual Research Corporation Technical Report RC78-BT-27, December 1978. 
APPENDIX B

Source Code for Radiation Heat Flux

and Configuration Factor Computer Program 


\section{PROGRAM FLUX}

C

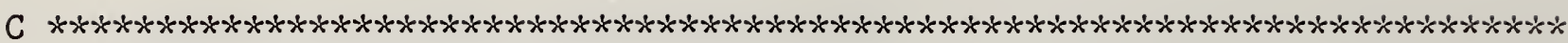

$C *$ This program calculates the heat fluxes received by targets at *

$C *$ user-specified distances from a fire. The program accounts for *

$C *$ the effect of wind on the flame size and shape. The flame is *

$C *$ assumed to be cylindrical in shape. *

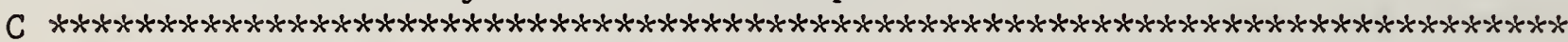

C

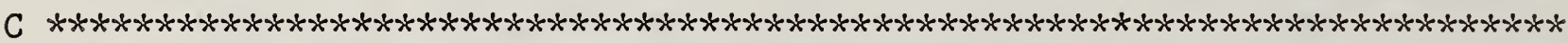

C

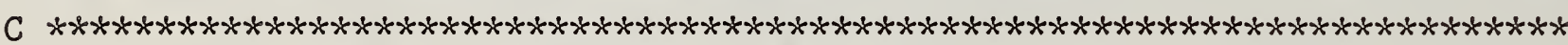

$\mathrm{C}$

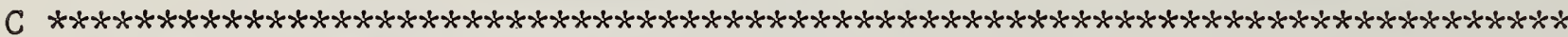

C

C

ASUR - Surface area of the flame

BETA - Angle of inclination of the target

CHI - Fraction of the energy release lost as radiation

D - Diameter of the fire (meters)

DM - Diameter of the fire (feet)

EMISS - Emissivity of the flame

F - Actual view factor for flame to target

FH - Horizontal portion of view factor

FLGTH - Flame length (meters)

FLGTHF - Flame length (feet)

FM - Maximum view factor for flame to target

FV - Vertical portion of view factor

$\mathrm{G}$ - Acceleration of gravity

$\mathrm{H}$ - Vertical height of the flames (meters)

HM - Vertical height of the flames (feet)

HC - Heat of combustion of the fuel

HLGTH - Vertical height of the flames (meters)

HLGTHF - Vertical height of the flames (feet)

HR - Flame height to radius ratio

MDOT - Mass flow rate of fuel

MDOTAF - Mass flow rate of fuel per unit burner area

ND - Number of distances for flux calculations

NRING - Number of rings used for view factor

NSECT - Number of sections used for view factor

NW - Maximum number of wind speeds

NWIND - Actual number of wind speeds

QDOT - Flux received at a given target

$\mathrm{R}$ - - Radius of burn area

RHOA - Density of air

RHOF - Density of fuel vapors

$\mathrm{S}$ - Dimensionless distance to target

THETA - Angle of inclination of the flame

TRANS - Transmissivity of the atmosphere

TRGDIF - Distance from flame to target (feet)

TRGDIS - Distance from flame to target (meters)

VDOT - Volume flow rate of fuel

VISC - Viscosity of air

WNDSM - Wind speed (meters per second) 
C WNDSPD - Wind speed (miles per hour)

C Z - Height of the target above the ground

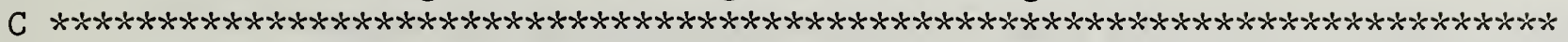

C

PARAMETER $(\mathrm{NW}=10, \mathrm{ND}=200)$

DIMENSION WNDSPD(NW), WNDSM(NW)

DIMENSION QDOT(NW)

REAL MDOT, MDOTAF

DATA G, SIGMA / 9.8,5.67E-11/

DATA RHOA, VISC / 1.1,2.0E-5/

$\mathrm{PI}=4 . * \mathrm{ATAN}(1$.

$\mathrm{PHI}=0.0$

NRING $=10$

NSECT $=20$

C

C

C

Open the output files and enter the data.

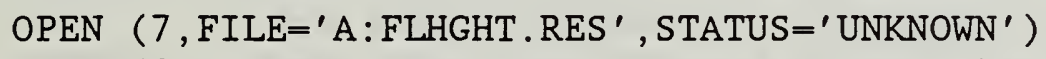

OPEN ( 8, FILE $=$ 'A : FLUX.RES' , STATUS $=$ ' UNKNOWN' $^{\prime}$ )

WRITE $(6,1000)$

$\operatorname{READ}(5, *)$ RHOF, HC

RHOF $=16.018 *$ RHOF

$\mathrm{HC}=2.326 * \mathrm{HC}$

WRITE $(6,1010)$

$\operatorname{READ}(5, *)$ EMISS, TRANS

WRITE $(6,1020)$

$\operatorname{READ}(5, *)$ VDOT, DM, HM

VDOT $=0.0283 *$ VDOT

$\mathrm{D}=0.3048 * \mathrm{DM}$

$\mathrm{H}=0.3048 * \mathrm{HM}$

MDOT $=$ VDOT $*$ RHOF

MDOTAF $=\mathrm{MDOT} /(\mathrm{PI} * \mathrm{D} * * 2 / 4$.

WRITE $(6,1030)$

$\operatorname{READ}(5, *) \mathrm{CHI}$

WRITE $(6,1040)$

READ $(5, *)$ BETA

WRITE $(6,1050)$

$\operatorname{READ}(5, *) \mathrm{Z}$

WRITE $(6,1060)$

$\operatorname{READ}(5, *)$ NWIND

WRITE $(6,1070)$ NWIND

$\operatorname{READ}(5, *)$ (WNDSPD (I) , I=1, NWIND)

DO $10 I=1$, NWIND

10 CONTINUE

$\operatorname{WNDSM}(I)=\operatorname{WNDSPD}(I) *(1 . / 3600) * 5280 *$.

C

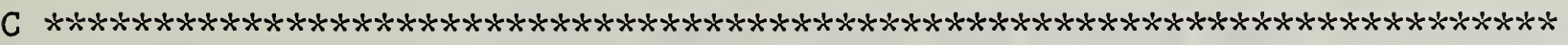

C

CALCULATIONS

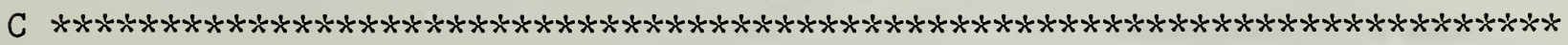

$\mathrm{C}$

$\mathrm{R}=\mathrm{D} / 2$.

$\mathrm{HR}=\mathrm{H} / \mathrm{R}$ 
TRGDIF $=\mathrm{DM} / 2 .+0.5$

C

C

C

C

C

C

C

C

C

C

C

C

C

C

C

C

C

*

Begin loop to determine the
size and shape of the flame.

DO $30 I=1$, NWIND

IF (WNDSM(I).LE.0.0) THEN

Calculate view factor.

$A=(H R * * 2+S * * 2+1) /.(2 . * S)$

$B=(1 .+S * * 2) /(2 . * S)$

$\operatorname{TN} 1=\operatorname{ATAN}(\operatorname{SQRT}(((B+1) *.(\mathrm{~S}-1))) /.((B-1) *.(\mathrm{~S}+1))))$.

$\operatorname{TN} 2=\operatorname{ATAN}(\operatorname{SQRT}(((\mathrm{A}+1) *.(\mathrm{~S}-1))) /.((\mathrm{A}-1) *.(\mathrm{~S}+1)))$.

$\mathrm{FH}=(1 . / \mathrm{PI}) *(((\mathrm{~B}-(1 . / \mathrm{S})) /(\mathrm{SQRT}(\mathrm{B} * * 2-1))). * \mathrm{TN} 1-(((\mathrm{A}-(1 \cdot / \mathrm{S})) /$

$(\operatorname{SQRT}(A * * 2-1))). * \operatorname{TN} 2))$

TN3 $=\operatorname{ATAN}(\mathrm{HR} / \mathrm{SQRT}(\mathrm{S} * * 2-1)$.

$\operatorname{TN} 4=\operatorname{ATAN}(\operatorname{SQRT}((\mathrm{S}-1) /.(\mathrm{S}+1))$.

$\mathrm{FV}=(1 . / \mathrm{PI}) *(1 . / \mathrm{S} * \mathrm{TN} 3-(\mathrm{HR} / \mathrm{S}) *(\operatorname{TN} 4-(\mathrm{A} /(\operatorname{SQRT}(\mathrm{A} * * 2-1))). * \mathrm{TN} 2))$

$\mathrm{FM}=\mathrm{SQRT}(\mathrm{FH} * * 2+\mathrm{FV} * * 2)$

Calculate the flame surface area and the heat flux.

ASUR $=P I * D * H$

$\mathrm{QDOT}(\mathrm{I})=$ EMISS $*$ TRANS $*$ FV $*$ CHI $*$ MDOT $*$ HC $/$ ASUR

FLGTHF $=\mathrm{H} / 0.3048$

THET $=0.0$

WRITE $(7, *)$ WNDSPD $(I)$, FLGTHF, THET

ELSE

Calculate the flame angle of tilt, flame length, and view factor.

CALL ANGLE (D, WNDSM(I), RHOA, VISC, G, RHOF, THETA)

THET $=$ THETA $* 180 . /$ PI

CALL FLMEXT (D, WNDSM(I) , RHOA, G, RHOF , MDOTAF , HRR, FLGTH)

CALL VIEW (D , FLGTH, THET , DIS , Z , PHI , BETA, NRING , NSECT , FM, FH, FV ,

*

F)

Calculate the flame surface area and the heat flux.

ASUR $=$ PI $* D * F L G T H$

$\mathrm{QDOT}(\mathrm{I})=\mathrm{EMISS} * \mathrm{TRANS} * \mathrm{FV} * \mathrm{CHI} * \mathrm{MDOT} * \mathrm{HC} / \mathrm{ASUR}$

HLGTH $=$ FLGTH*COS $($ THETA $)$

FLGTHF $=$ FLGTH/0.3048 


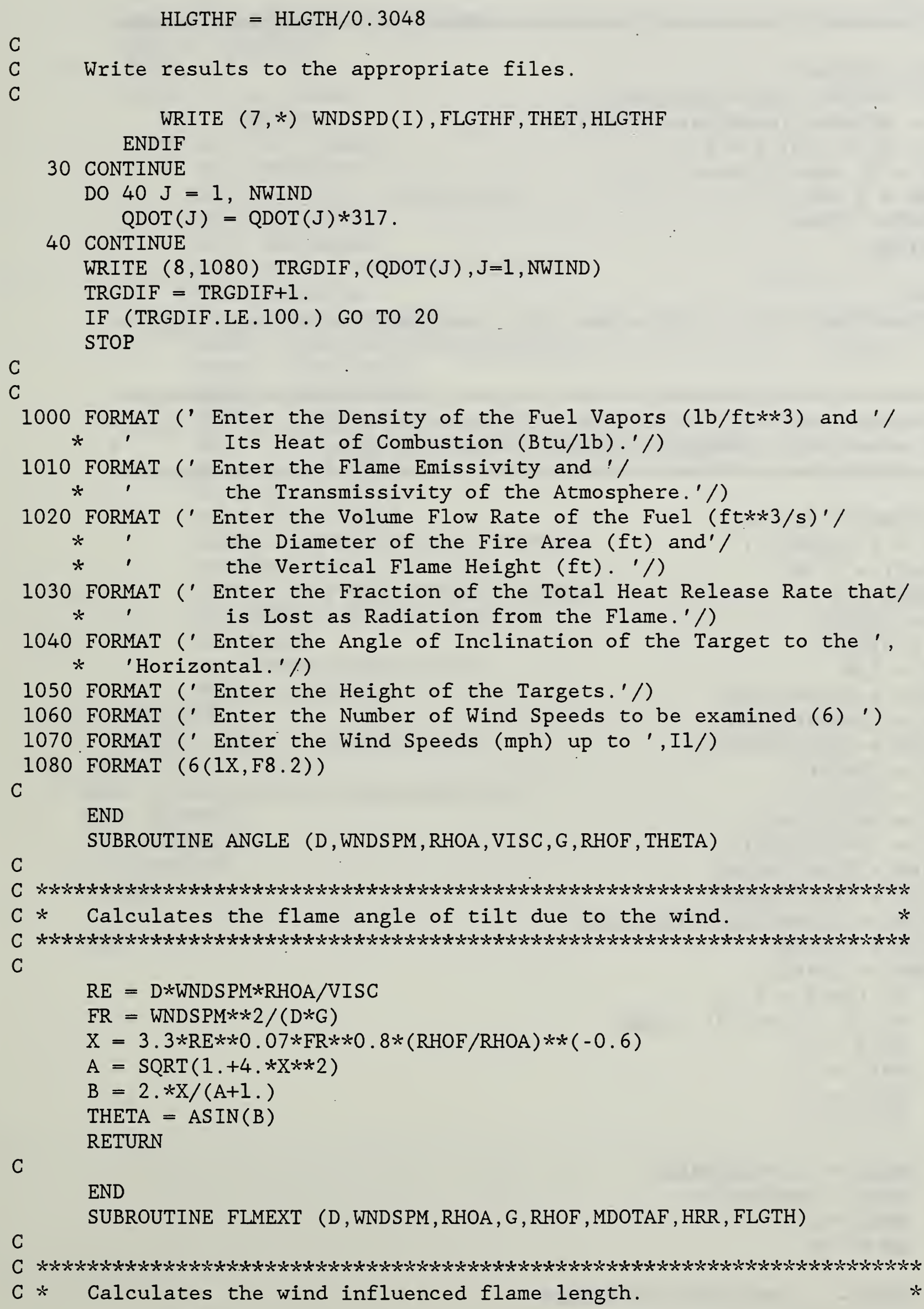


$\mathrm{C}$

REAL MDOTAF

$A=\operatorname{MDOTAF} /(\operatorname{RHOA} *(\operatorname{SQRT}(D * G)))$

$\mathrm{B}=\operatorname{WNDSPM} /((\mathrm{G} * \mathrm{MDOTAF} * \mathrm{D} / \mathrm{RHOF}) * *(1 . / 3)$.

IF (B.LE.1.0) $B=1.0$

$\mathrm{HD}=55 . * A * * 0.67 * B * *(-0.21)$

$\mathrm{HRR}=2 . * \mathrm{HD}$

FLGTH $=\mathrm{HD} * \mathrm{D}$

RETURN

C

END

SUBROUTINE VIEW (D , FLEN, ALPHA, DIST , Z, PHI , THETA, NRING , NSECT , FMAX, FH

$\mathrm{C}$

* , FV , F)

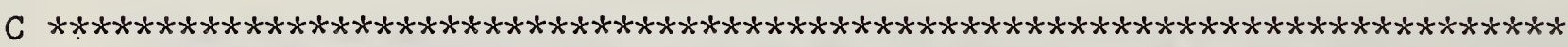

$C *$ Computes the view factor from a differential element to the fire *

$C *$ by numerically summing elements of the fire shape. *

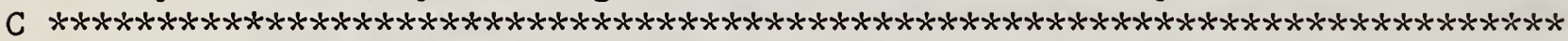

$\mathrm{C}$

DIMENSION FACTR( 3 )

$\mathrm{PI}=4 . *$ ATAN $(1$.

TWOPI $=2 . * P I$

DBASE $=1$.

$\mathrm{H}=$ FLEN $/ \mathrm{D}$

$\mathrm{S}=\mathrm{DIST} / \mathrm{D}$

$\mathrm{ZI}=\mathrm{Z} / \mathrm{D}$

PHII $=\mathrm{PHI} * \mathrm{PI} / 180$.

$\mathrm{AL}=\mathrm{ALPHA} * \mathrm{PI} / 180$.

THET $=$ THETA $* P I / 180$.

$\mathrm{SA}=\mathrm{SIN}(\mathrm{AL})$

$\mathrm{CA}=\operatorname{COS}(\mathrm{AL})$

$\mathrm{X} 1=\mathrm{S} * \operatorname{COS}(\mathrm{PHII})$

$\mathrm{Y} 1=-\mathrm{S} * \mathrm{SIN}(\mathrm{PHII})$

RING $=$ FLOAT (NRING)

SECT $=$ FLOAT (NSECT)

ASUBD $=\mathrm{PI} * \mathrm{H} *$ DBASE $/(\mathrm{RING} * \mathrm{SECT})$

DELH $=$ H/RING

RBASE $=$ DBASE $/ 2$.

DO 80 ICASE $=1,3$

GO TO $(10,20,30)$, ICASE

$10 \quad \mathrm{RN} 1 \mathrm{X}=0$.

$\mathrm{RN} 1 \mathrm{Y}=0$.

$\mathrm{RN} 1 \mathrm{Z}=1$.

GO TO 40

C

$20 \quad \mathrm{RN} 1 \mathrm{X}=-1 . * \operatorname{COS}(\mathrm{PHII})$

RN1Y $=\operatorname{SIN}($ PHII)

$\mathrm{RN} 1 \mathrm{Z}=0$.

GO TO 40

C

$30 \mathrm{RN} 1 \mathrm{X}=-1 . * \operatorname{COS}(\mathrm{PHII}) * \operatorname{SIN}(\mathrm{THET})$ 


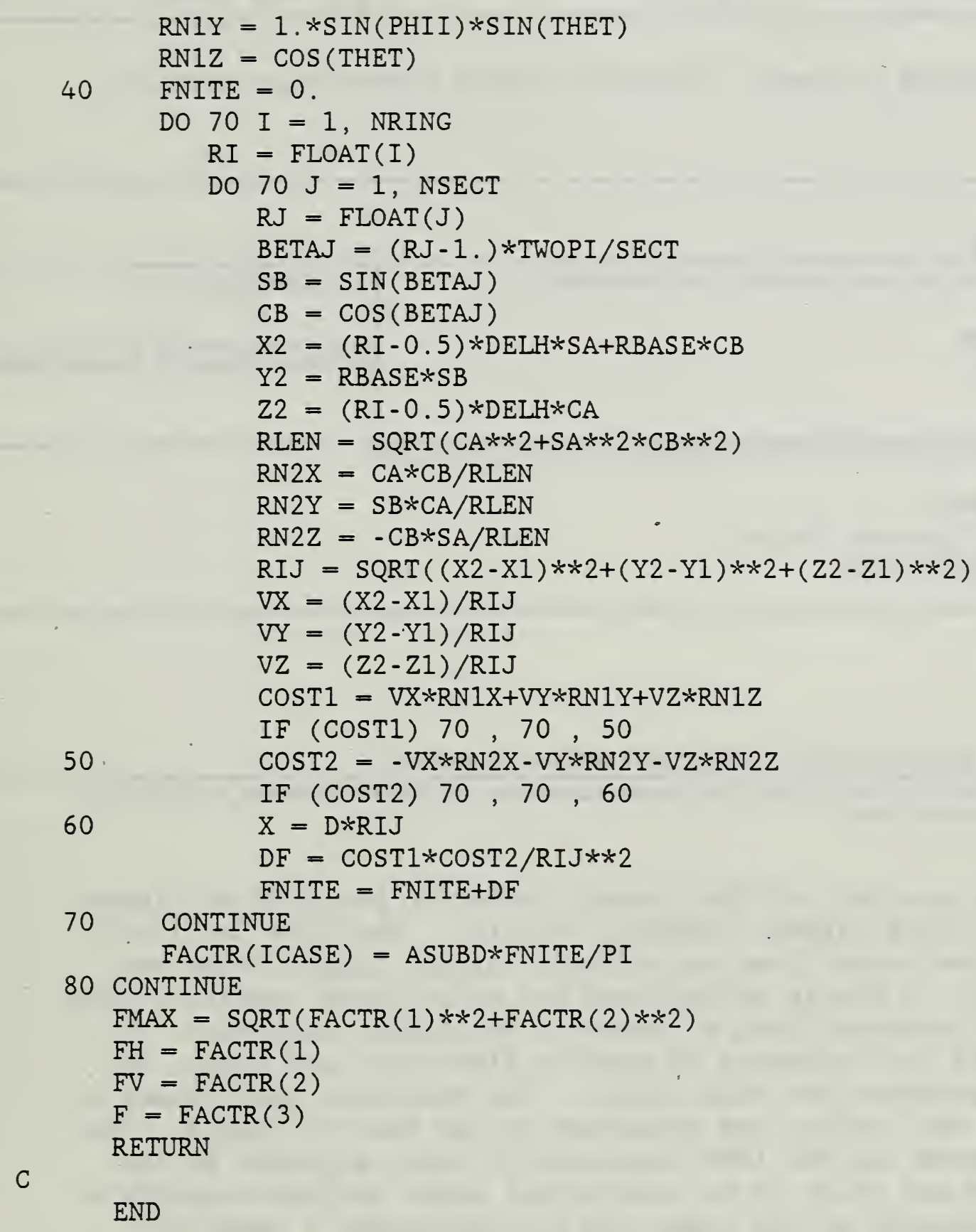

END 
U.S. DEPT. OF COMM.

BIBLIOGRAPHIC DATA

SHEET (See instructions)
1. PUBLICATION OR REPORT NO. NBSIR $-88 / 3755$
2. Performing Organ. Report No. 3. Publication Date

May 1988

4. TITLE AND SUBTITLE

Naval Fire Fighting Trainers - Thermal Effects Association with the $19 F 4$ FFT

5. $A \cup T H O R(S)$

David W. Stroup

6. PERFORMING ORGANIZATION (If joint or other than NBS, see instructions)

7. Contract Grant No.

NATIONAL BUREAU OF STANDARDS

U.S. DEPARTMENT OF COMMERCE

GAITHERSBURG, MD 20899

9. SPONSORING ORGANIZATION NAME AND COMPLETE ADDRESS (Street, City, State, ZIP)

United States Navy

Naval Training Systems Center

Orlando, FL $32813-7100$

10. SUPPLEMENTARY NOTES

Document describes a computer program; SF-185, FIPS Software Summary, is attached.

11. ABSTRACT (A 200-word or less factual summary of most significant information. If document includes a significant bibliogrophy or literature survey. mention it here)

This report presents an analysis of the thermal radiation produced by flames from the U.S. Navy 19F4 Fire Fighter Training facility. The 19F4 facility is used to simulate airplane crash fires on aircraft carrier flight decks and aircraft carrying ships. A simple methodology for calculating radiative heat transfer to targets is developed from a review of available literature. Of particular importance is the influence of wind on flame size and shape, the calculation procedure accounts for this effect. The radiation heat fluxes at various distances from the trainer are presented in the form of graphs. The fluxes received by a crane and the $19 F 4$ instructor's tower adjacent to the facility are calculated and shown to be substantial under certain conditions. Recommendations for placement of the crane and the instructor's tower are provided.

12. KEY WOROS (Six to twelve entries: alphabetical order; capitalize only proper names; and separate key words by semicolons)

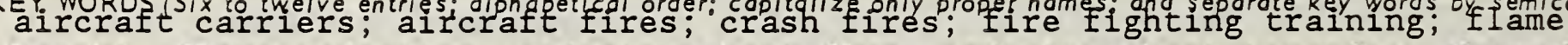
height; flame radiation; radiation heat flux; radiative heat transfer; thermal radiation; training devices; wind effects

13. AVAILABILITY

X Unlimited

For Official Distribution. Do Not Release to NTIS

$\square$ Order From Superintendent of Documents, U.S. Government Printing Office, Washington, DC 20402.

X] Order From National Technical Information Service (NTIS), Springfield, VA 22161
14. NO. OF PRINTED PAGES

15. Price

$\$ 13.95$ 

